\title{
Host-guest-mediated epitope presentation on self-assembled peptide amphiphile hydrogels
}

Carlos Redondo-Gómez ${ }^{a, b}$, Soraya Padilla Lopategui ${ }^{a, b}$, Helena S. Azevedo ${ }^{a, b}$, Alvaro Mata $^{a, b, c, d, e^{*}}$

a School of Engineering \& Materials Science, Queen Mary University of London, London E1 4NS, UK

b Institute of Bioengineering, Queen Mary University of London, London E1 4NS, UK

c School of Pharmacy, University of Nottingham, University Park, Nottingham NG7 2RD, UK

$\mathrm{d}$ Department of Chemical and Environmental Engineering, University of Nottingham, University Park, Nottingham NG7 2RD, UK

e Biodiscovery Institute, University of Nottingham, University Park, NG7 2RD, UK

*Corresponding author:

Alvaro Mata

a.mata@nottingham.ac.uk 


\section{ABSTRACT}

A key feature in biomaterial design is the incorporation of bioactive signals into artificial constructs to stimulate tissue regeneration. Most currently used hydrogel cell culture systems depend on the covalent attachment of extracellular matrix (ECM)-derived peptides to either macromolecular units or smaller self-assembling building blocks, thereby restricting biosignal presentation and adaptability. However, new ways to rationally incorporate adhesion epitopes through non-covalent interactions would offer opportunities to better recreate the dynamic and reversible nature of the native ECM. Here we report on a non-covalent epitope presentation approach mediated by host-guest interactions. Using peptide amphiphile hydrogels we demonstrate that the adamantane/ $\beta$-cyclodextrin (Ada/ $\beta \mathrm{CD}$ ) pair can be used to anchor RGDS cell adhesion signals onto self-assembled hydrogels via host-guest interactions. We evaluate hydrogel morphological and rheological properties as well as fibroblast attachment, organisation, and spreading when cultured atop these scaffolds. This host-guest mediated epitope display might lead to new self-assembling hydrogels for improved cell culture applications as well tissue engineering and regenerative medicine. 


\section{INTRODUCTION}

Progress in supramolecular chemistry has led to growing control over molecular self-assembly and provided robust approaches to design biomaterials with increasing biomimicry, structural complexity, and functionality. ${ }^{1,2}$ Remarkable examples of functional self-assembling systems based on polymers, ${ }^{3}$ sugars ${ }^{4}$ nucleic acids, ${ }^{5}$ proteins, ${ }^{6}$ and their combination ${ }^{7}$ have been reported.

Research on synthetic constructs for tissue engineering and regenerative medicine applications has evidenced the importance of mimicking morphological, ${ }^{8}$ mechanical, ${ }^{9}$ and biochemical ${ }^{10}$ aspects of the extracellular matrix $(\mathrm{ECM}) .{ }^{11}$ Hydrogels are particularly well-suited to provide these characteristics and have consequently drawn attention as cell scaffolds for in vitro and in vivo studies. $^{12}$

Hydrogels based on self-assembling peptides have gained increasing attention given their capacity to form nanofibrillar networks with biologically relevant viscoelastic and mass transport properties and precisely display bioactive epitopes. ${ }^{13,14}$ Peptide amphiphiles (PAs) are one class of self-assembling peptides that have demonstrated ability to emulate ECM bioactivity ${ }^{15,16}$ as well as have tuneable structural and physical properties. ${ }^{17-20}$ These molecules offer the opportunity to engineer hydrogels with enhanced complexity by co-assembling with biomolecules such as proteins ${ }^{21-23}$ and polysaccharides ${ }^{24}$ as well as other components such as low molecular weight gelators ${ }^{25}$ and laponite. ${ }^{26}$ Furthermore, the possibility to generate non-covalent nanofiber networks rendering a high-density of biofunctional epitopes makes PA-based hydrogels a highly attractive platform for tissue engineering applications. For example, RGD-based sequences have been successfully incorporated into PA platforms for cell adhesion and cell delivery studies. These platforms include variations on linear, ${ }^{27}$ branched, or cyclic ${ }^{28}$ peptide conformations, the presence of a spacer in the PA sequence, ${ }^{29}$ modulation of epitope density along nanofiber $\operatorname{axis}^{30}$, and hierarchical structuration of peptide 
constructs. $^{31}$ In addition, PA-based hydrogels have been used to guide cell migration ${ }^{32,33}$ and differentiation ${ }^{34}$ in vitro as well as in vivo regeneration of blood vessels, ${ }^{15}$ cartilage, ${ }^{35}$ axons, ${ }^{36}$ bone, ${ }^{37}$ and enamel. ${ }^{27}$

These examples evidence the opportunities that PA-based hydrogels offer as bioactive ECM analogues. Despite great efforts have been made to exert temporal control of epitope presentation in PA-based hydrogels, ${ }^{38}$ more work on simple methods for hydrogel post-functionalization is necessary. ${ }^{39}$ Though the use of light ${ }^{40}$ or enzymes ${ }^{41}$ has proved effective on the modulation of bioactivity in polymer-based systems, we have demonstrated that host-guest interactions (such as the formation of the inclusion complex between $\beta$-cyclodextrin and adamantane motifs $)^{42,43}$ may offer an effective approach to aid in this effort.

Binding of host-guest motifs is dictated by a dynamic equilibrium between their unbound and bound states, in such way, if structurally defined host-guest complexes break apart they exhibit the capability to reform again. ${ }^{42}$ Even though this approach has been vastly employed to modify physico-chemical properties of polymer-based hydrogels, ${ }^{39}$ it has not been yet fully exploited in supramolecular hydrogels. We have recently reported on $\beta$-cyclodextrin/adamantane PA hydrogels in which hostguest groups are used to enhance interfiber interactions and consequently enable modulation of mechanical properties of the hydrogel. ${ }^{18}$ In a similar manner, we hypothesized this approach may offer new opportunities to modulate bioactivity and epitope presentation in PA hydrogels. ${ }^{44}$

Here, we report on the host-guest-mediated binding of RGDS motifs to self-assembled PA nanofibers as a strategy to improve biological epitope presentation, and potentially drive future temporal control, and adaptability within PA hydrogel networks. Firstly, the synthesis and characterisation of two anionic adamantane-bearing PAs is presented, then their ability to be incorporated into co-assembled nanofibers is explored from a spectroscopic and rheological point of view. Next, we choose the most 
suitable adamantane-PA derivative to undergo non-covalent functionalisation with a complementary RGDS- $\beta$-cyclodextrin derivative. Lastly, we assess the biological functionality of this epitope anchoring and presenting approach via in vitro cell adhesion experiments.

\section{EXPERIMENTAL SECTION}

Materials. All reagents were purchased from Sigma-Aldrich and used without any further purification unless otherwise stated. Phosphate buffered saline (PBS 1x), Dulbecco's Modified Eagle's Medium (DMEM), Hank's Balanced Salt Solution (HBSS), Penicillin/Streptomycin (P/S), and Foetal Bovine Serum (FBS), were obtained from Gibco (Life Technologies).

Peptide synthesis and purification. Peptide amphiphiles and $\boldsymbol{\beta C D - R G D S}$ were synthesised using modifications of previously reported solid phase peptide synthesis (SPPS) procedures. ${ }^{18,45}$ Peptides were purified using reverse phase high performance liquid chromatography (RP-HPLC) and their identity was confirmed using electrospray ionisation mass spectrometry (ESI-MS). Further details are provided in the Electronic Supplementary Information.

Transmission electron microscopy (TEM). Peptide $0.05 \mathrm{wt} \%$ in HEPES solutions $(10 \mathrm{mM}, \mathrm{pH}=7.4)$ were negatively stained as follows: solutions were drop-casted on holey carbon-coated copper TEM grids (Agar Scientific, Stansted, UK), solution excess was blotted after 5 min incubation, then incubated one minute with $2 \%$ uranyl acetate. Grids were then washed with ultrapure water for $30 \mathrm{~s}$ and air dried for $24 \mathrm{~h}$ at room temperature before imaging. Bright-field TEM images were acquired on a JEOL 1230 TEM operated at $80 \mathrm{kV}$. All the images were recorded by a Morada CCD camera (Image Systems) and at least six areas were analysed (corresponding to $n \geq 100$ PA nanofibers). 
Circular dichroism (CD). Assessment of secondary structure of self-assembled nanostructures was undertaken in a $1 \mathrm{~mm}$ path-length quartz cuvette placed in a Pistar-180 spectropolarimeter (Applied Photophysics, Surrey, UK) equipped with a Peltier temperature controller, under a constant nitrogen purging at a constant pressure of $0.7 \mathrm{MPa}$ and temperature of $25^{\circ} \mathrm{C}$. Peptides were dissolved in HEPES $10 \mathrm{mM}$ saline (155 mM NaCl, pH 7.4) reaching a final concentration of $0.01 \mathrm{wt} \%$. Far UV spectra were recorded from 190 to $270 \mathrm{~nm}$ a wavelength step of $0.5 \mathrm{~nm}$. Each represented spectrum is the average of three consecutive spectra. Temperature variable CD experiments were carried out between $10{ }^{\circ} \mathrm{C}$ and $70{ }^{\circ} \mathrm{C}$, with a heating rate of $1{ }^{\circ} \mathrm{C} / \mathrm{min}$, and collecting three consecutive spectra every $10^{\circ} \mathrm{C}$.

Hydrogel preparation. Peptides were dissolved in HEPES buffer at a concentration of $1.5 \mathrm{wt} \%$, mixed thoroughly according to the desired Filler-PA/Host-guest ratio, incubated at $80{ }^{\circ} \mathrm{C}$ for $30 \mathrm{~min}$ and let to slowly cool down to room temperature, this is called "peptide stock solution". Subsequently, a 30 $\mu \mathrm{L}$ drop of peptide stock solution was placed onto a polydimethylsiloxane (PDMS) substrate, injected with $15 \mu \mathrm{L}$ of $\mathrm{CaCl}_{2} 100 \mathrm{mM}$ and incubated at $28{ }^{\circ} \mathrm{C}$ for $24 \mathrm{~h}$ to afford $1 \mathrm{wt} \%$ self-assembled hydrogels in all cases.

Peptide string formation. An aliquot of $15 \mu \mathrm{L}$ peptide stock solution was manually dragged from a pipette onto a glass slide covered by a thin layer of $\mathrm{CaCl}_{2} 100 \mathrm{mM}$ solution. Noodle-shaped viscoelastic strings were obtained and left to age for at least 15 minutes before using.

Polarized light microscopy. An optical microscope with polarising filters (Olympus BX60 Upright compound light microscope) was used to visualise birefringence in the noodle-shaped hydrogel structures. At least three samples were measured per condition $(n \geq 3)$. 
Scanning electron microscopy (SEM). PA hydrogels underwent stepwise dehydration, critical point drying and gold coating before SEM imaging. Initially peptide hydrogels were stepwise dehydrated by immersion in increasingly concentrated ethanol solution $(20 \%, 50 \%, 70 \%, 80 \%, 90 \%, 95 \%$, $100 \%$ ), for 5 min twice in each solution. Dehydrated samples were dried using a critical point dryer (K850, Quorum Technologies, UK) and gold coated before imaging on an Inspect F50 (FEI Company, the Netherlands) ( $\mathrm{n} \geq 3)$.

Nuclear magnetic resonance (NMR). $\mathbf{E}_{\mathbf{3}} \mathbf{G}_{3}$ Ada-PA was dissolved in $\mathrm{D}_{2} \mathrm{O}$ at a final concentration of 10-12 mg/mL (using NaOD to promote peptide solubility) and 1 equivalent of $\boldsymbol{\beta C D}$-RGDS was added to the mixture. Two dimensional NOESY NMR spectra were recorded on a Bruker AvanceNEO 600 spectrometer at room temperature.

Rheology. Hydrogels' rheological characterization was performed with a DHR-3 Rheometer (TA Instruments, USA) using an $8 \mathrm{~mm}$ diameter parallel plates geometry. G' (storage modulus) and $\mathrm{G}^{\prime \prime}$ (loss modulus) were monitored by amplitude and frequency sweeps. $\mathrm{G}^{\prime}$ and $\mathrm{G}^{\prime \prime}$ moduli were measured at $25{ }^{\circ} \mathrm{C}$ and a constant frequency of $1 \mathrm{~Hz}$ in the $0.01 \%-10 \%$ strain during the amplitude sweep, while the oscillation frequency experiments were carried out at a $0.1 \%$ fixed strain along $0.1-100$ Hz.

Cell culture. All cell culture experiments were conducted with a NIH-3T3 fibroblast cell line. NIH3 T3 fibroblasts were cultured with DMEM medium supplemented with $10 \%$ fetal bovine serum (FBS) and $1 \%$ penicillin and $1 \%$ streptomycin. Cells were maintained in a humidified $5 \% \mathrm{CO}_{2}$ atmosphere at $37^{\circ} \mathrm{C}$. 
In vitro cell response on the hydrogels. On a typical experiment, $5 \mu \mathrm{L}$ aliquot of a $10 \mathrm{mM}$ PA ternary mixture of $\mathbf{E}_{\mathbf{3}}-\mathbf{P A} / \mathbf{E}_{\mathbf{3}} \mathbf{G}_{3}$ Ada-PA $\subset \boldsymbol{\beta C D}$-RGDS were injected within $50 \mu \mathrm{L}$ of $\mathrm{CaCl}_{2} 100 \mathrm{mM}$ solution ( $1 \mathrm{mM}$ peptide final concentration). After 30 minutes gelation, the excess of $\mathrm{CaCl}_{2}$ was removed and 30000 NIH-3T3 cells were seeded onto the hydrogels. Hydrogels $(n \geq 3)$ were incubated for $30 \mathrm{~min}$, $1 \mathrm{~h}$ and $3 \mathrm{~h}$ in supplemented DMEM before fixation, staining and imaging as follows. Cells were fixed using a $4 \mathrm{wt} \%$ paraformaldehyde (PFA) 1x PBS solution overnight at $5{ }^{\circ} \mathrm{C}$, washed with $\mathrm{PBS}$, blocked with a BSA $2 \mathrm{wt} \%$ in $1 \mathrm{x}$ PBS solution for $2 \mathrm{~h}$, washed with PBS. Samples were firstly staining with DAPI (Sigma-Aldrich) at a 1/5000 dilution for 5 min (cell nuclei staining), washed with 1x PBS, then stained with Rhodamine-Phalloidin R415 (Sigma-Aldrich) at a 1/250 dilution in 1x PBS for 40 min (F-Actin staining). Confocal fluorescent images were acquired using a Leica TCS SP2 and Zeiss LSM710 confocal microscopes. Cell morphology and spreading was monitored using Fiji ImageJ software (http://imagej.nih.gov/ij) (NIH, USA) to quantify the ratio of cell area to cell nuclei area (n $\geq 50$ cells per condition).

\section{RESULTS AND DISCUSSION}

\section{Rationale of the study}

The material design exploits a modular approach to anchor bioactive signals on self-assembled PA nanofibers via specific non-covalent complexations. A complementary host-guest pair was chosen by covalently attaching adamantyl (Ada) guest moieties to PAs, so these can further bind a complementary $\beta$-cyclodextrin epitope-bearing host derivative and be ultimately displayed in hydrogel scaffolds for cell culture. ${ }^{43}$ In this fashion, the effect of covalent derivatisation of negatively charged PA molecules with Ada units was initially investigated by designing two negatively charged guest PA molecules isostructural to $\mathbf{E}_{3}-\mathbf{P A}\left(\mathrm{C}_{16}-\mathrm{V}_{3} \mathrm{~A}_{3} \mathrm{E}_{3}\right)$. This filler PA will further act as the nanofibers' main constituent (filler PA) before assembling the host-guest pairs, thus diluting epitope density presentation in the resulting hydrogels. 


\section{Synthesis of building blocks}

Filler $\mathbf{E}_{\mathbf{3}}$-PA and guest-PAs $\mathbf{E}_{\mathbf{3}} \mathbf{A d a}-\mathbf{P A}$ and $\mathbf{E}_{\mathbf{3}} \mathbf{G}_{\mathbf{3}}$ Ada-PA were synthesized using standard solidstate peptide synthesis (SSPS) followed by purification through reverse phase high-performance liquid chromatography (RP-HPLC) as previously described. ${ }^{18}$ Further synthesis and characterization details can be found in the Electronic Supporting Information (Fig. S1-4, Table S1). Both Ada-bearing guest-PAs comprise an aliphatic palmitoyl tail $\left(\mathrm{C}_{16^{-}}\right)$at their $\mathrm{N}$-terminus, followed by a $\beta$-sheet forming amino acid sequence $\left(-\mathrm{V}_{3} \mathrm{~A}_{3^{-}}, \mathrm{V}\right.$ : valine, $\mathrm{A}$ : alanine) that ensures the formation of high-aspect ratio cylindrical nanofibers. Three ionisable glutamic acid residues (-E $3^{-}$, E: glutamic acid) are included immediately after in order to promote nanofiber solubility in water. A combination of peptoid synthesis and copper(I)-catalyzed alkyne-azide cycloaddition (CuAAC) coupling approaches were used to incorporate the Ada units (as part of a peptoid sidechain, i.e. attached to a nitrogen atom from the peptide backbone instead of an alpha carbon ) close to the C-terminus of $\mathbf{E}_{\mathbf{3}} \mathbf{A d a}$-PA (Scheme

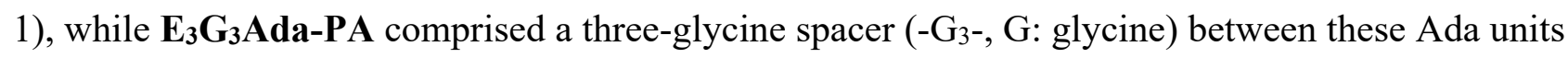
and the PA C-terminus. This uncharged spacer has a rather flexible nature and spaces out the Ada units some $12.2 \AA$ from the charged glutamic acid residues domain. ${ }^{29}$ This spacer was also included to facilitate presentation of Ada units after co-assembly with the filler PA (Scheme 1).

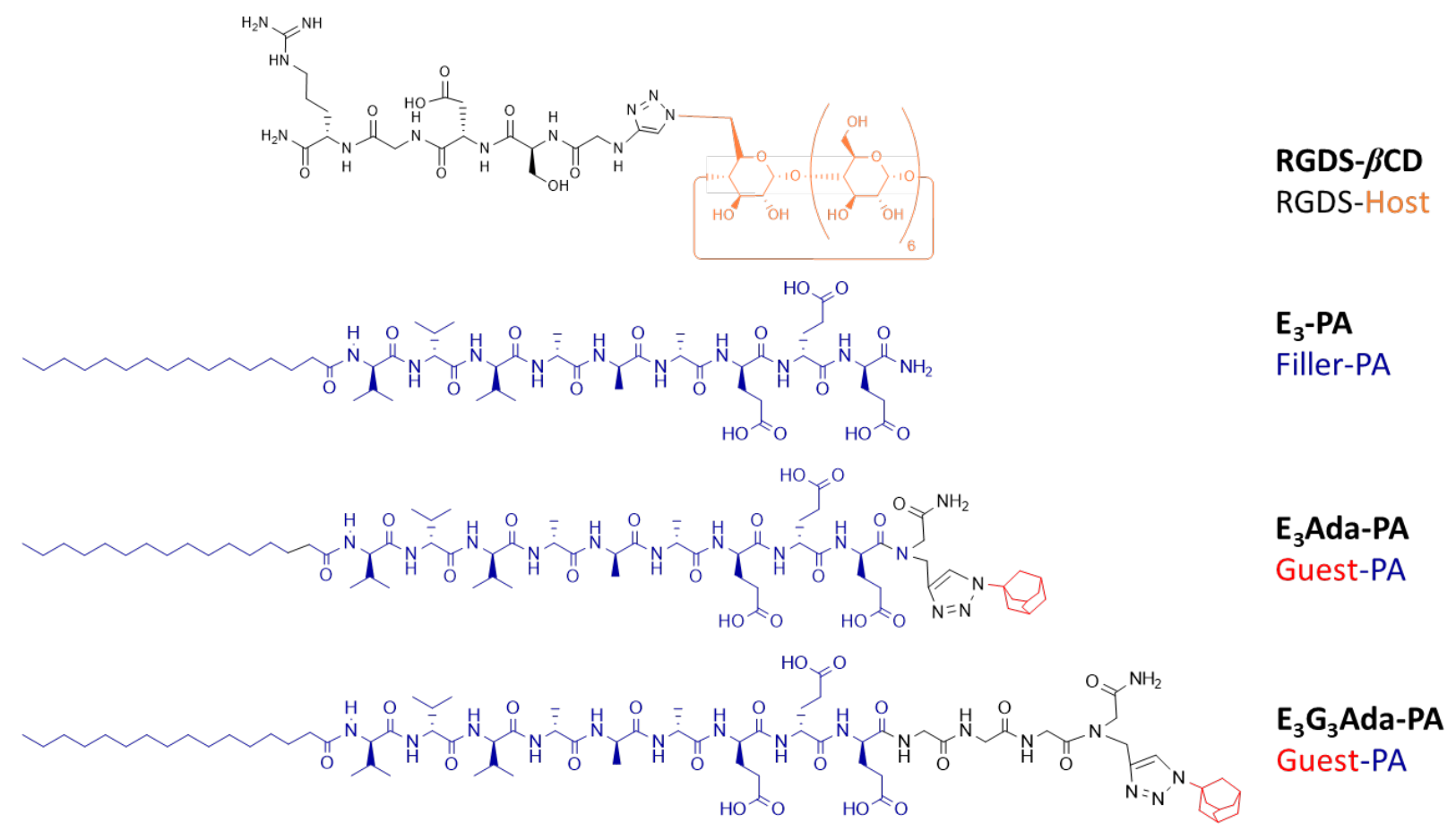


Scheme 1. Molecular structures of the self-assembling peptides reported in this study. All PA molecules are isostructural to the negatively charged $\mathbf{E}_{\mathbf{3}}-\mathbf{P A}, \mathbf{E}_{\mathbf{3}} \mathbf{A d a}-\mathbf{P A}$ and $\mathbf{E}_{\mathbf{3}} \mathbf{G}_{\mathbf{3}} \mathbf{A d a}-\mathbf{P A}$ bear an adamantane residue. $\boldsymbol{\beta C D}$-RGDS contains a $\beta$-cyclodextrin Host moiety that is complementary to adamantane residues present in the corresponding Guest-PA molecules.

\section{Effect of Adamantyl residues on PA self-assembly}

Nanofiber self-assembly of unmixed filler PA $\left(\mathbf{E}_{\mathbf{3}}-\mathbf{P A}\right)$ and both guest-PAs ( $\mathbf{E}_{\mathbf{3}} \mathbf{A d a}-\mathbf{P A}$ and $\mathbf{E}_{3} \mathbf{G}_{3}$ Ada-PA) was investigated using transmission electron microscopy (TEM). TEM micrographs revealed the presence of nanofibers of around 11-13 nm in diameter in both guest-PA solutions at 25 ${ }^{\circ} \mathrm{C}$ while $\mathbf{E}_{3}$-PA originated longer but slightly thinner nanofibers of around 8-10 $\mathrm{nm}$ in diameter (Figure 1B-D). $\mathbf{E}_{\mathbf{3}}$-PA originated stand-alone nanofibers (Figure 1B), whereas nanofibers from both guest-PAs exhibited a slight tendency to form small bundles (Figure 1C-D). Furthermore, at this temperature, E- $\mathbf{3}$-PA nanofibers exhibited longer micron-long nanofibers while guest-PAs originated smaller submicron aggregates. This is as indication that the presence of Ada residues on PA nanofibers may modify the geometric packing parameters of traditional PA backbones. Ada residues are rather spherical in shape and of non-polar nature, which allows them to establish van der Waals and hydrophobic interactions amid adjacent units, promoting their aggregation. This is in agreement with previous reports by our group on positively charged PAs bearing adamantyl units exhibiting a greater tendency to form bundles and raft-like objects at millimolar concentration regimes (Figure 1C-D). ${ }^{18}$ 
A)

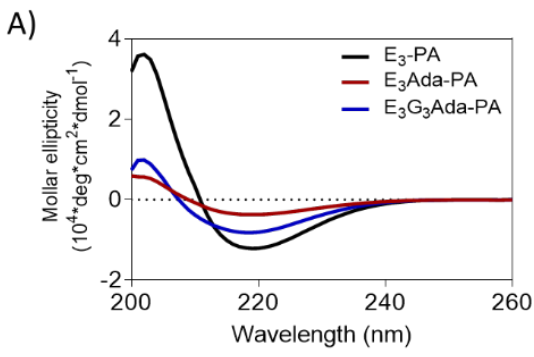

E)

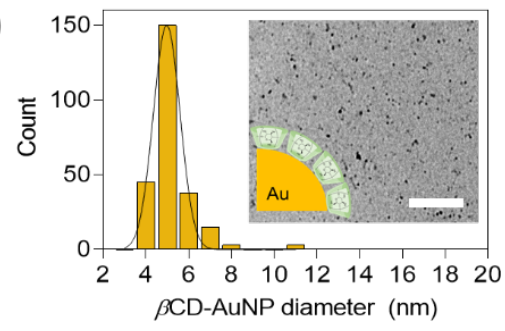

$E_{3}-P A$

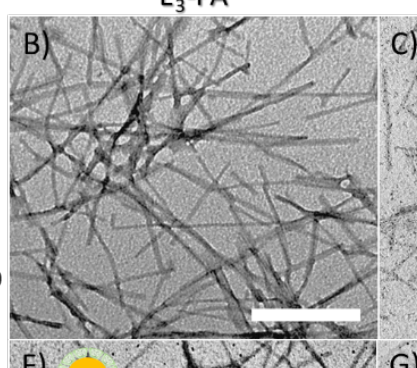

$E_{3}$ Ada-PA

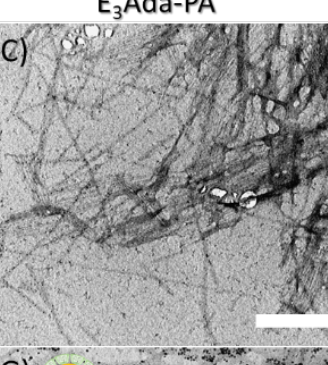

$E_{3} G_{3}$ Ada-PA

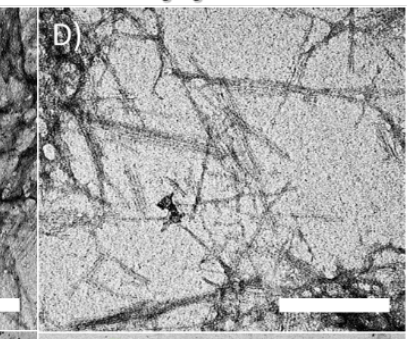

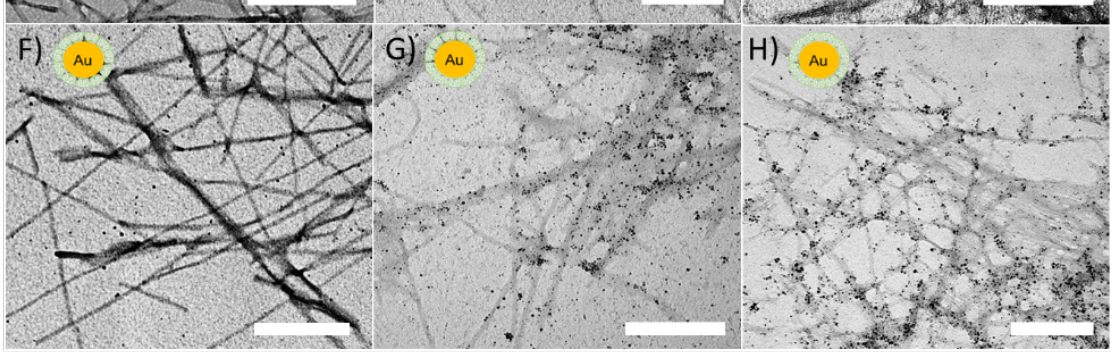

Figure 1. Self-assembly of the herein reported anionic PA derivatives in HEPES buffer. A) CD spectra of $\mathbf{E}_{3}-\mathbf{P A}, \mathbf{E}_{3} \mathbf{A d a}-\mathbf{P A}$, and $\mathbf{E}_{3} \mathbf{G}_{3} \mathbf{A d a}-\mathbf{P A}$ indicating the persistence of $\beta$-sheets. B-D) TEM images indicate the presence of nanofibers from all three $\mathbf{E}_{\mathbf{3}}-\mathbf{P A}, \mathbf{E}_{\mathbf{3}} \mathbf{A d a}-\mathbf{P A}$, and $\mathbf{E}_{\mathbf{3}} \mathbf{G}_{\mathbf{3}} \mathbf{A d a}-\mathbf{P A}$ solutions (scale bars $=250 \mathrm{~nm}$ ). E) Characterisation of $\beta$-cyclodextrin-capped gold nanoparticles ( $\beta$ CD-AuNPs) used to track the presence of Ada residues (scale bar $=50 \mathrm{~nm}$ ). F-H) TEM images of $\mathbf{E}_{3}-\mathbf{P A}, \mathbf{E}_{3} \mathbf{A d a}-\mathbf{P A}$, and $\mathbf{E}_{3} \mathbf{G}_{3}$ Ada-PA samples incubated with $\beta \mathrm{CD}$-AuNPs (scale bars $=250 \mathrm{~nm}$ ).

\section{Adamantyl moieties affect nanofiber conformation}

As slight interfiber bundling was observed on amid guest-PAs, as seen by TEM imaging (Figure 1C, D). Consequently, we investigated whatever additional repercussions the presence of Ada units may have on the secondary structure of the self-assembled nanofibers. CD spectroscopy revealed that all PAs ( $\mathbf{E}_{\mathbf{3}}-\mathbf{P A}, \mathbf{E}_{\mathbf{3}} \mathbf{A d a}-\mathbf{P A}$, and $\left.\mathbf{E}_{\mathbf{3}} \mathbf{G}_{\mathbf{3}} \mathbf{A d a}-\mathbf{P A}\right)$ presented a $\beta$-sheet signature signal, ${ }^{29}$ with a positive maximum signal centered at $202 \mathrm{~nm}$ and a negative minimum at $219 \mathrm{~nm}$ with no evident shifts among the signals (Figure 1A). This absence of wavelength shifts can be interpreted as no interference of Ada units in the twisting levels of the $\beta$-sheets at nanofiber cores. ${ }^{19}$ Variations in the peak intensities were observed in the three PAs: $\beta$-sheet signals were more intense for $\mathbf{E}_{\mathbf{3}}-\mathbf{P A}, \mathbf{E}_{\mathbf{3}} \mathbf{G}_{\mathbf{3}} \mathbf{A d a}$-PA exhibited an almost four-fold reduction in $\beta$-sheet signal intensity, while $\mathbf{E}_{\mathbf{3}}$ Ada-PA showed the least intense signal with a six-fold intensity reduction compared to $\mathbf{E}_{\mathbf{3}}-\mathbf{P A}$. This intensity reduction can be attributed to the re-arrangement of nanofiber $\beta$-sheets into shorter and less regular ones as a result of the presence of Ada moieties. These results demonstrate that the three-glycine spacer may be beneficial for $\beta$-sheet formation as it spaces out adjacent hydrophobic Ada units, allowing the 
formation of more ordered $\beta$-sheets at the nanofiber core. ${ }^{19}$ In other words, $\mathbf{E}_{\mathbf{3}} \mathbf{G}_{\mathbf{3}} \mathbf{A d a} \mathbf{A} \mathbf{P A}$ forms stronger $\beta$-sheets than $\mathbf{E}_{\mathbf{3}} \mathbf{A d a}-\mathbf{P A}$ but not as strong as $\mathbf{E}_{\mathbf{3}}-\mathbf{P A}$.

\section{Non-covalent complexation of Adamantyl units}

To confirm the presence of Ada binding units on the surface of $\mathbf{E}_{\mathbf{3}} \mathbf{A d a}-\mathbf{P A}$ and $\mathbf{E}_{\mathbf{3}} \mathbf{G}_{\mathbf{3}} \mathbf{A d a} \mathbf{A} \mathbf{P}$ nanofibers, TEM imaging was performed using $\beta$-cyclodextrin-capped gold nanoparticles $(\beta C D$ AuNPs, synthesised and characterised as reported by Shi and co-workers). ${ }^{46} \beta \mathrm{CD}$-AuNPs were found to exhibit a negative zeta potential, a diameter of $5.6 \pm 0.9 \mathrm{~nm}$ (approximately corresponding to the radius of our PA nanofibers), and about $210 \beta \mathrm{CD}$ units bound to the surface of each AuNP (Figure 1E). $\mathbf{E}_{\mathbf{3}} \mathbf{A d a}-\mathbf{P A}$ and $\mathbf{E}_{\mathbf{3}} \mathbf{G}_{\mathbf{3}} \mathbf{A d a}-\mathbf{P A}$ were incubated with an excess of $\beta C D$-AuNPs and significant clusters of adsorbed particles in the proximity of nanofibers were found for both guest-PAs nanofibers (Figure $1 \mathrm{G}, \mathrm{H})$. E $\mathbf{E}_{\mathbf{3}}$-PA controls exhibited little to none $\beta \mathrm{CD}$-AuNP adsorption onto the nanofibers, indicating that host-guest non-covalent binding might be the main contributor to $\beta \mathrm{CD}-\mathrm{AuNP}$ attachment to nanofibers (Figure 1F) rather than an electrostatically driven mechanism. Similar approaches to track motifs on PA systems using gold-nanoparticles have been reported. ${ }^{47}$ These results confirm that the presence of Ada residues in PA monomers does not prevent nanofiber selfassembly and also allows for the establishment of further host-guest interactions with $\beta \mathrm{CD}$ binding motifs. This was further probed through cell culture studies discussed later in this study.

\section{Structuring PA gels containing Adamantyl residues}

Both $\mathbf{E}_{\mathbf{3}}$ Ada-PA and $\mathbf{E}_{\mathbf{3}} \mathbf{G}_{\mathbf{3}} \mathbf{A d a}-\mathbf{P A}$ offer inherent capacities to bind complementary host-units. The possibility to affix pendant Ada guest units from these guest-PAs to canonical PA nanofibers was explored by co-assembling them with an excess of the filler $\mathbf{E}_{\mathbf{3}}$-PA. Several reasons justify the use of $\mathbf{E}_{3}$-PA as filler/spacer. First, as $\mathbf{E}_{\mathbf{3}}$-PA contains the same peptide backbone (Scheme 1) as both guestPAs, a reasonable degree of complementarity amid these units was predicted. Second, given that the ultimate goal of appending Ada units to self-assembled nanofibers is their binding with a suitable 
epitope-bearing $\beta \mathrm{CD}$, the longitudinal spacing of Ada units along PA nanofibers might contribute to improve further bioactivity when in presence of cells. ${ }^{28}$

Morphological and mechanical properties of these co-assembled nanofibers might be mostly dictated by those of the filler $\mathbf{E}_{\mathbf{3}}-\mathbf{P A}$ as this represents the predominant component in the fibers. This hypothesis led us to assess the ability of $\mathbf{E}_{\mathbf{3}}$-PA filler molecules to confer hierarchical ordering levels via the well-understood entropy-driven dehydration-rehydration process reported by Zhang and coworkers. $^{32}$ To explore this possibility Ada-pendant co-assembled nanofibers, solutions of containing an excess of E-PA (80 mol\%) and either guest-PA (20 mol\%) were prepared. These solutions were heated at $80^{\circ} \mathrm{C}$, slowly cooled down to room temperature, and manually dragged from a pipette onto a $\mathrm{CaCl}_{2}$ bath, obtaining transparent noodle-shaped viscoelastic strings similar to those of $\mathbf{E}_{\mathbf{3}}-\mathbf{P A}$ solutions. ${ }^{32}$ Polarised light microscopy was used to assess the presence of birefringent domains in $\mathbf{E}_{\mathbf{3}}$ PA noodle-like strings, ${ }^{32}$ as well as in its 80:20 mixtures with either $\mathbf{E}_{\mathbf{3}} \mathbf{A d a}-\mathbf{P A}$ or $\mathbf{E}_{\mathbf{3}} \mathbf{G}_{\mathbf{3}} \mathbf{A d a}-\mathbf{P A}$ (Figure 2A-C). SEM images revealed that highly parallel oriented filaments were found in pure $\mathbf{E}_{\mathbf{3}^{-}}$ PA strings as well as in guest-PA mixtures (Figure 2D-F). These results demonstrate that the presence of Ada motifs at the surface of co-assembled PA nanofibers neither disrupts fiber formation nor interferes with their nano- to microscale hierarchical self-assembly. 

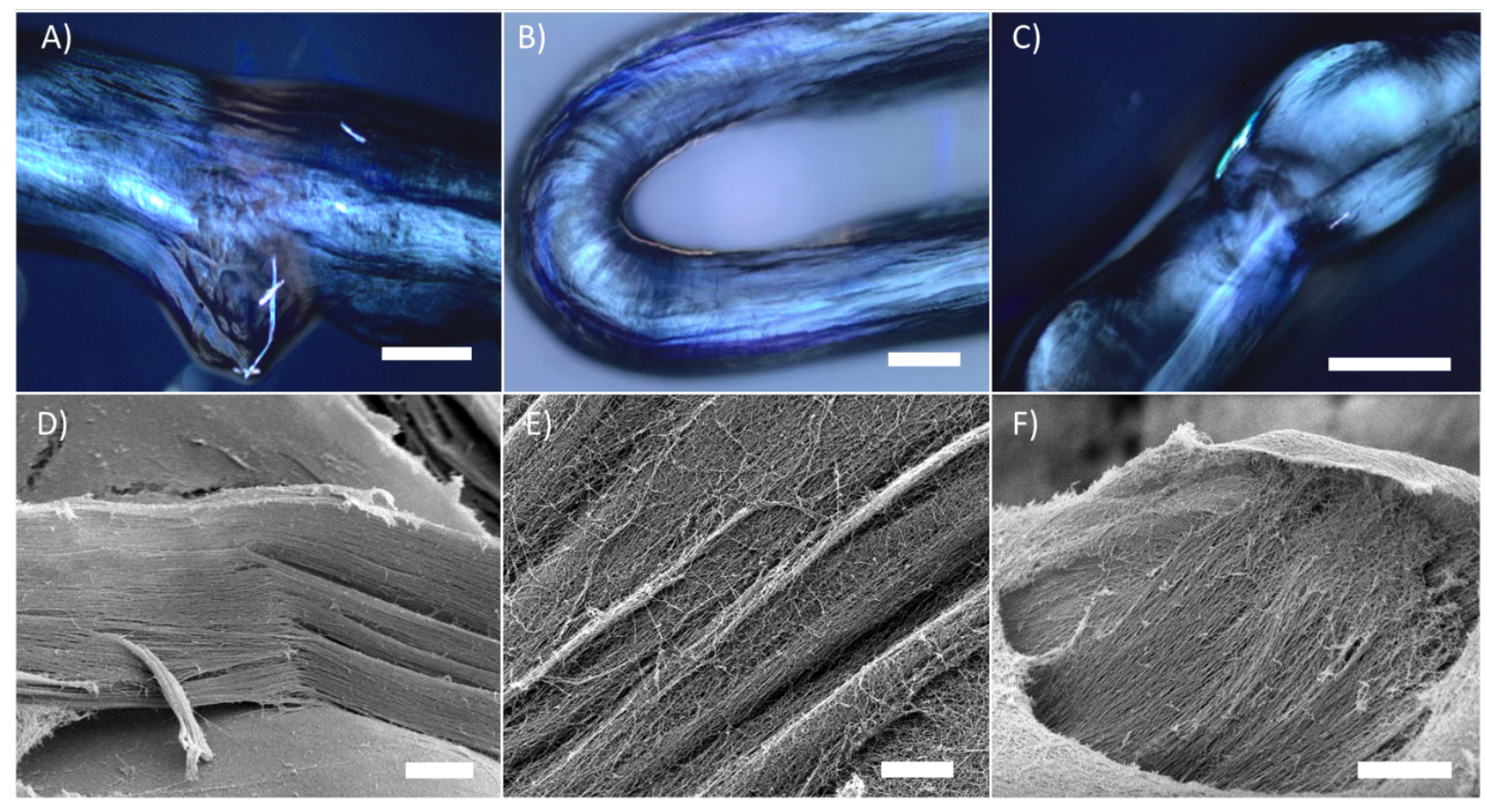

Figure 2. Microstructure characterisation of $\mathbf{E}_{\mathbf{3}}-\mathbf{P A}, \mathbf{E}_{\mathbf{3}}-\mathbf{P A} / \mathbf{E}_{\mathbf{3}} \mathbf{A d a}-\mathbf{P A}$ and $\mathbf{E}_{\mathbf{3}}-\mathbf{P A} / \mathbf{E}_{\mathbf{3}} \mathbf{G}_{\mathbf{3}} \mathbf{A d a}-\mathbf{P A}$ aligned hydrogels. A - C) Polarized light microscopy showing the birefringence of single hydrogel strings indicating alignment along the string elongated axis in A) $\mathbf{E}_{\mathbf{3}}-\mathbf{P A}$, B) $\mathbf{E}_{\mathbf{3}}-\mathbf{P A} / \mathbf{E}_{\mathbf{3}} \mathbf{A d a}-\mathbf{P A}$ 80:20 $(\mathrm{mol} \%)$ and C) $\mathbf{E}_{\mathbf{3}}-\mathbf{P A} / \mathbf{E}_{\mathbf{3}} \mathbf{G}_{\mathbf{3}} \mathbf{A d a}-\mathbf{P A} 80: 20$ (mol\%) (scale bars = $1 \mathrm{~mm}$ ). D) SEM micrographs of $\mathbf{E}_{\mathbf{3}}-$ PA, E) $\mathbf{E}_{3}-\mathbf{P A} / \mathbf{E}_{3}$ Ada-PA 80:20 (mol\%) and F) $\mathbf{E}_{\mathbf{3}}-\mathbf{P A} / \mathbf{E}_{\mathbf{3}} \mathbf{G}_{\mathbf{3}} \mathbf{A d a}-\mathbf{P A}$ 80:20 (mol\%) hydrogels evidencing nanofiber alignment due to elongational flow (scale bars $=5 \mu \mathrm{m}$ ).

\section{Rheological characterisation of Ada-containing hydrogels}

To confirm that the incorporation of Ada motifs does not affect the mechanical properties of coassembled hydrogel strings, we used oscillatory rheology to quantify their stiffness. Thermally treated mixtures of $\mathbf{E}_{\mathbf{3}}-\mathbf{P A}$ and different ratios of either $\mathbf{E}_{\mathbf{3}} \mathbf{A d a}-\mathbf{P A}$ or $\mathbf{E}_{\mathbf{3}} \mathbf{G}_{\mathbf{3}} \mathbf{A d a}-\mathbf{P A}$ were gelled by injection into an excess of $\mathrm{CaCl}_{2}$. E् $\mathbf{3}$ Ada-PA-containing hydrogels displayed a loss of transparency with an increasing fraction of $\mathbf{E}_{\mathbf{3}} \mathbf{A d a}-\mathbf{P A}$, which was reflected on their mechanical properties. Only a 5 mol\% of $\mathbf{E}_{\mathbf{3}}$ Ada-PA caused a decrease in the storage modulus $\left(\mathrm{G}^{\prime}\right)$ of the co-assembled hydrogels, from $24 \mathrm{kPa}$ in $100 \mathrm{~mol} \% \mathbf{E}_{\mathbf{3}}$-PA hydrogels to $\sim 15 \mathrm{kPa}$ in 95:5 $\mathbf{E}_{\mathbf{3}}$-PA/ $\mathbf{E}_{\mathbf{3}} \mathbf{A d a}-\mathbf{P A}$ mixtures. Increasing fractions of $\mathbf{E}_{\mathbf{3}} \mathbf{A d a}-\mathbf{P A}$ led to decreasing G' values, indicating poor co-assembling compatibility between $\mathbf{E}_{\mathbf{3}}$-PA and $\mathbf{E}_{\mathbf{3}} \mathbf{A d a}$-PA monomers. This decrease in the hydrogels stiffness can be attributed to the presence of shorter nanofibers, probably due to $\beta$-sheet disruption as a consequence of their 
close proximity of Ada units (Figure 3A). Similar reports in PA hydrogel stiffness loss can be found after adding up to $10 \%$ of epitope presenting PA. ${ }^{29}$

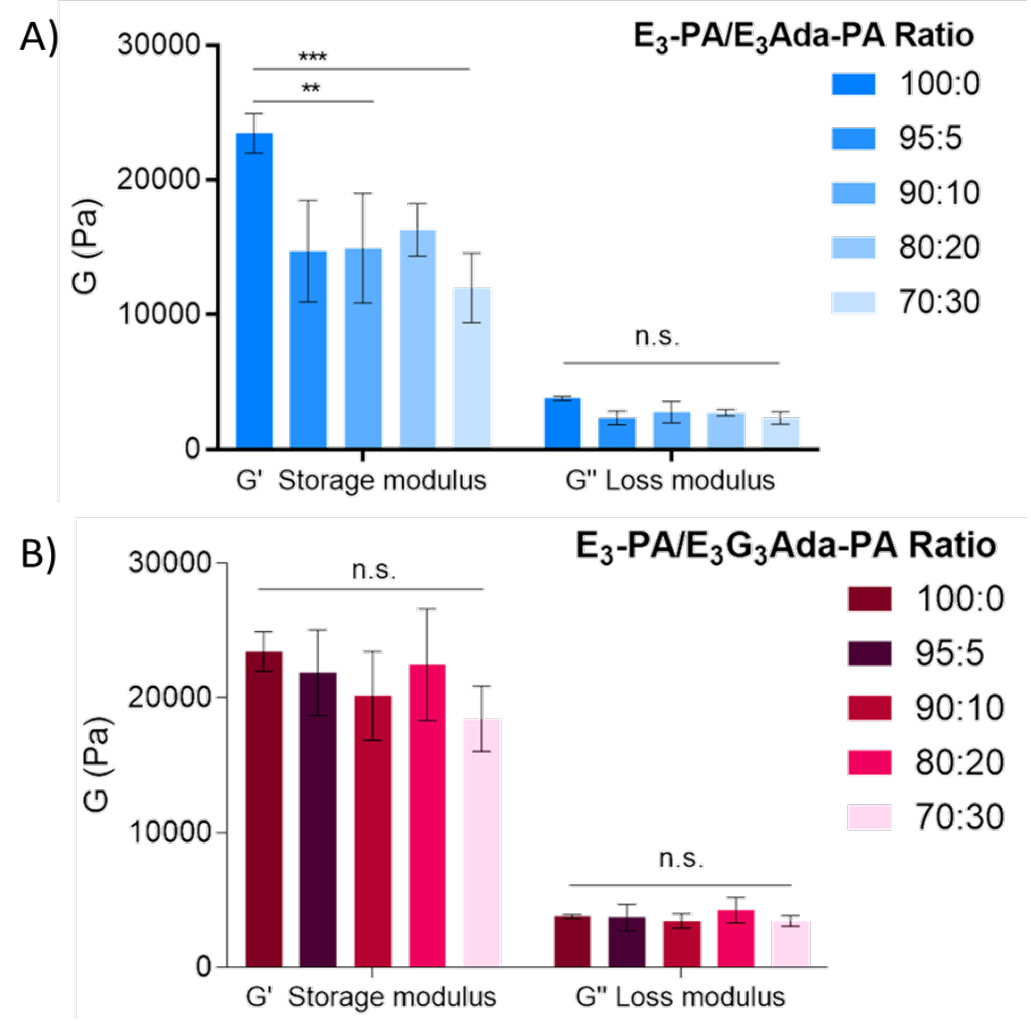

Figure 3. Rheological characterisation of co-assembled $\mathbf{E}_{\mathbf{3}}-\mathbf{P A} / \mathbf{E}_{\mathbf{3}} \mathbf{A d a}-\mathbf{P A}$ and $\mathbf{E}_{\mathbf{3}}-\mathbf{P A} / \mathbf{E}_{\mathbf{3}} \mathbf{G}_{\mathbf{3}} \mathbf{A d a}-\mathbf{P A}$ hydrogels. A) Storage $\left(\mathrm{G}^{\prime}\right)$ and loss $\left(\mathrm{G}^{\prime \prime}\right)$ moduli values of hydrogels containing different $\mathbf{E}_{\mathbf{3}}$ PA/ $/ \mathbf{E}_{3}$ Ada-PA ratios $\left(1 \mathrm{wt} \%,\left[\mathrm{CaCl}_{2}\right]=100 \mathrm{mM}\right)$ determined by oscillatory rheology. B) Coassembled $\mathbf{E}_{\mathbf{3}}-\mathbf{P A} / \mathbf{E}_{\mathbf{3}} \mathbf{G}_{3} \mathbf{A d a}-\mathbf{P A}$ hydrogels showed no $G$ ' nor $G$ "' significant dependence on the content of the Adamantane-bearing PA $(* * * \mathrm{p}<0.001 ; * * \mathrm{p}<0.01$; n.s. no significant difference; $\mathrm{n}$ $>3$ ). Binding studies with $\beta \mathrm{CD}$ are presented further in the study.

On the other hand, co-assembled hydrogels with increasing $\mathbf{E}_{\mathbf{3}} \mathbf{G}_{\mathbf{3}} \mathbf{A d a}$-PA content remained transparent up to $30 \mathrm{~mol} \%$ of Ada-containing fractions and exhibited no significant variation in stiffness compared to $100 \mathrm{~mol} \% \mathbf{E}_{\mathbf{3}}$-PA hydrogels. In this co-assembled configuration, the presence of the three-glycine spacer played a key role in increasing co-assembly compatibility of the $\mathbf{E}_{\mathbf{3}}$-PA with the Ada containing $\mathbf{E}_{\mathbf{3}} \mathbf{G}_{\mathbf{3}}$ Ada-PA. PA-based systems comprising shorter self-assembled fibers tend to exhibit inferior mechanical properties than those formed by longer fibers, ${ }^{48}$ most likely due to 
improved water trapping capacity in the resulting 3D hydrogel network. In this fashion, higher (and little-dependent on Ada content) G' values in $\mathbf{E}_{\mathbf{3}} \mathbf{G}_{\mathbf{3}}$ Ada-PA co-assembled gels are an indicative of longer self-assembled nanofibers than those originated by $\mathbf{E}_{\mathbf{3}}$ Ada-PA (Figure 3B), suggesting enhanced co-assembling compatibility of the former guest-PA with filler $\mathbf{E}_{\mathbf{3}}-\mathbf{P A}$. These results suggest that $\mathbf{E}_{\mathbf{3}} \mathbf{G}_{\mathbf{3}} \mathbf{A d a} \mathbf{A} \mathbf{P A}$ is a more suitable PA to further incorporate into co-assembled nanofibers than $\mathbf{E}_{\mathbf{3}}$ Ada-PA and highlight the importance of choosing appropriate co-assembling compatibilities between different PA self-assembling monomers. As a consequence, only $\mathbf{E}_{\mathbf{3}} \mathbf{G}_{\mathbf{3}} \mathbf{A d a - P A}$ was chosen as guest-PA for further binding studies with $\beta \mathrm{CD}$ as shown next.

\section{Non-covalent epitope presentation and cell adhesion response}

As rheological studies revealed that $\mathbf{E}_{\mathbf{3}} \mathbf{G}_{\mathbf{3}} \mathbf{A d a}-\mathbf{P A}$ was a suitable candidate to co-assemble with $\mathbf{E}_{\mathbf{3}}$ PA without compromising the resulting mechanical properties of the gel, we then investigated the formation of host-guest complexes involving these components. As $\beta$ CD-AuNPs binding studies indicated (Figure 1), $\mathbf{E}_{\mathbf{3}} \mathbf{G}_{\mathbf{3}}$ Ada-PA offers the possibility to bind to $\beta \mathrm{CD}$ motifs. Consequently, the RGDS- $\boldsymbol{\beta}$ CD derivative shown in Scheme 1 was chosen as the epitope-bearer RGDS-Host (Scheme S3). ${ }^{45}$ Unlike many cell adhesion peptides,${ }^{49} \mathrm{RGD}$ interactions with $\alpha v \beta 3$ and $\alpha 5 \beta 1$ integrin receptors and downstream signal transduction pathways are well understood in promoting cell adhesion..$^{50}$ In RGDS- $\boldsymbol{\beta C D}$, the cell binding domain is allocated on the primary rim of the $\beta$ CD units, thus exposing it on the PA nanofiber surface after binding to Ada cues via the opposite rim of the $\beta \mathrm{CD}$ macrocycle.

To demonstrate the formation of this 1:1 host-guest complex, we performed NMR studies in solution. Figure 4A shows ${ }^{1} \mathrm{H}-\mathrm{NMR}$ spectra corresponding to RGDS- $\boldsymbol{\beta}$ CD (whose H5 and H3 inner cavity protons are indicated), $\mathbf{E}_{\mathbf{3}} \mathbf{G}_{\mathbf{3}} \mathbf{A d a} \mathbf{A} \mathbf{P A}$ (whose protons from Ada units are indicated), and a 1:1 mixture of them. Here, some of the Ada protons have downfield shifted after binding to $\beta C D$ (Figure 4B), suggesting partial inclusion (Figure $4 \mathrm{C}$ ). To determine the placing of Ada residues inside the $\beta \mathrm{CD}$ 
cavity, nuclear Overhauser effect spectroscopy (NOESY) analysis was performed. Figure 4D depicts cross-peaks between Ada protons and $\mathrm{H} 5$ and $\mathrm{H} 3$ protons from $\beta \mathrm{CD}$ cavity (in green) that are completely absent in the NOESY spectrum of $\mathbf{E}_{\mathbf{3}} \mathbf{G}_{\mathbf{3}}$ Ada-PA alone (Figure S5). These results confirmed the formation of the non-covalent host-guest complex $\mathbf{E}_{\mathbf{3}} \mathbf{G}_{\mathbf{3}} \mathbf{A d a} \mathbf{A} \mathbf{P} A \subset \mathbf{R G D S}-\boldsymbol{\beta} \mathbf{C D}$ (Figure 4C) and the possibility to use Ada cues in PA nanofibers as anchoring points for RGDS- $\boldsymbol{\beta}$ CD cell binding motifs.
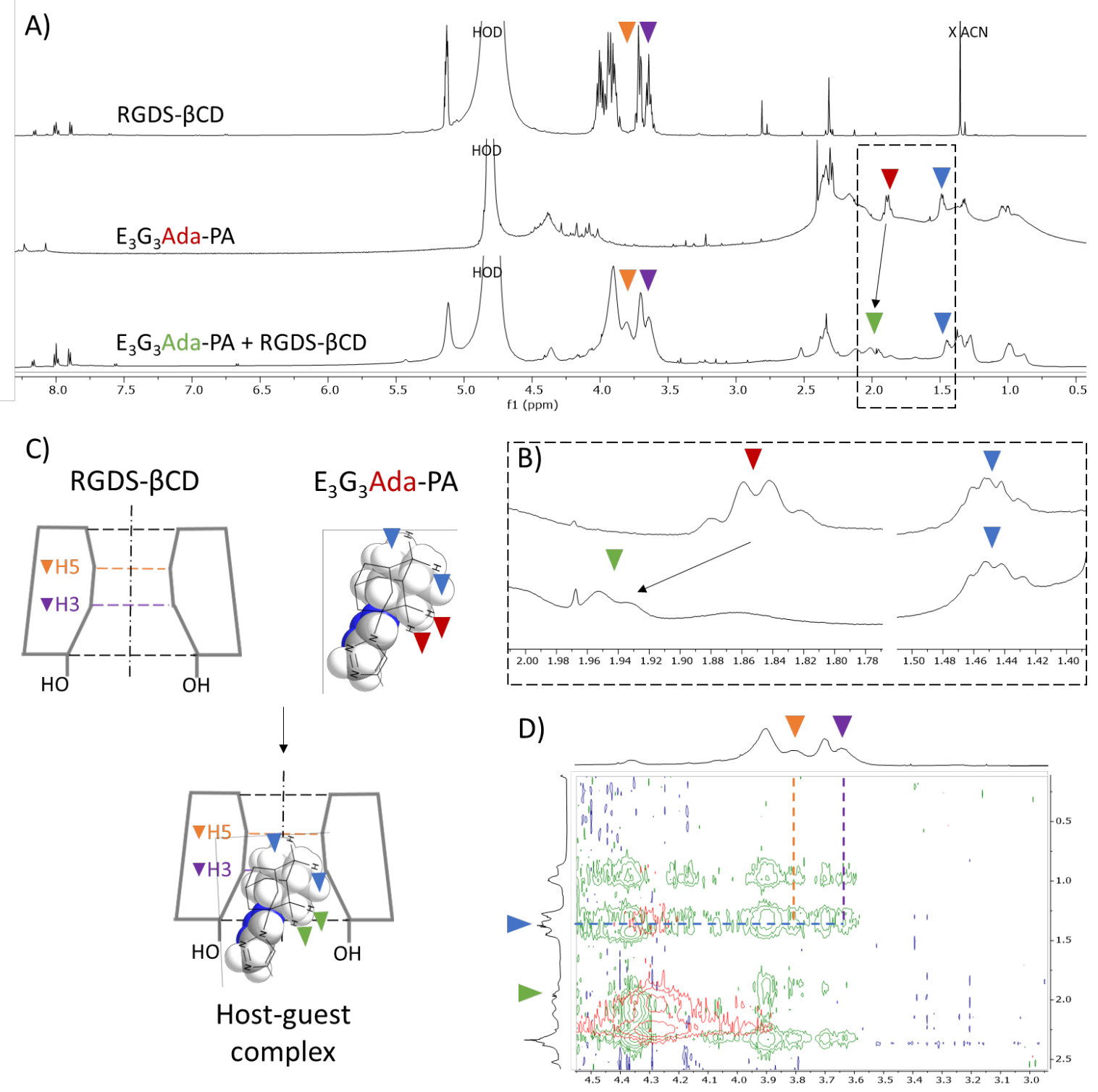

Figure 4. Spectroscopic characterisation of the host-guest inclusion complex formed between RGDS- $\boldsymbol{\beta C D}$ (Epitope-Host) and $\mathbf{E}_{3} \mathbf{G}_{3}$ Ada-PA (Guest-PA). A) ${ }^{1} \mathrm{H}-\mathrm{NMR}$ spectra corresponding to free RGDS- $\boldsymbol{\beta C D}$, free $\mathbf{E}_{\mathbf{3}} \mathbf{G}_{3}$ Ada-PA and an equimolar mixture in $\mathrm{D}_{2} \mathrm{O}, \mathrm{T}=298 \mathrm{~K}$, [Peptide] $=6.5$ mM. B) Zoom showing the downfield shift corresponding to Ada protons before and after complex formation. C) Schematics illustrating the formation of the 1:1 host-guest complex. D) NOESY 
demonstrating close proximity of Ada $\mathbf{E}_{\mathbf{3}} \mathbf{G}_{3}$ Ada-PA protons (green wedges) to H5 and H3 inner cavity RGDS- $\boldsymbol{\beta}$ CD protons (orange and purple wedges correspondingly) as cross peaks appear in the green traces, those peaks are absent in the $\mathbf{E}_{\mathbf{3}} \mathbf{G}_{\mathbf{3}} \mathbf{A d a} \mathbf{A} \mathbf{P A}$ spectrum in absence of RGDS- $\boldsymbol{\beta} \mathbf{C D}$ (red traces).

\section{$E_{3} G_{3} A d a-P A \subset R G D S-\beta C D$ effect on nanofiber formation}

Having collected experimental evidence of the formation of $\mathbf{E}_{\mathbf{3}} \mathbf{G}_{\mathbf{3}} \mathbf{A d a}-\mathbf{P A} \subset \mathbf{R G D S}-\boldsymbol{\beta C D}$ by spectroscopy, we then assessed the effect of this host-guest binding on self-assembled nanofiber morphology and PA conformation. CD studies indicated that host-guest complexation of RGDS- $\boldsymbol{\beta C D}$ units does not disrupt $\beta$-sheet formation, as a similar $\beta$-sheet signature was found in both free and RGDS- $\boldsymbol{\beta}$ CD-bound $\mathbf{E}_{\mathbf{3}} \mathbf{G}_{3}$ Ada-PA (Figure 5A). This result is in alignment with our previous study, in which similar host-guest complexations drove more dramatic conformational changes after the binding of host-guest-bearing PAs. ${ }^{18}$ Consequently, we speculate that the preservation of $\beta$-sheets in $\mathbf{E}_{3} \mathbf{G}_{3}$ Ada-PA $\subset$ RGDS- $\boldsymbol{\beta C D}$ is compatible with host-guest binding between these two short peptides. Furthermore, equimolar mixtures of $\mathbf{E}_{\mathbf{3}} \mathbf{G}_{\mathbf{3}}$ Ada-PA/RGDS- $\boldsymbol{\beta} \mathbf{C D}$ exhibited fibrous morphologies (Figure 5B), implying that host-guest complexations did not alter fiber formation in micro and millimolar concentration regimes, thus remaining suitable for co-assembly with the filler $\mathbf{E}_{\mathbf{3}}-\mathbf{P A}$ in ternary hydrogels. 
A)
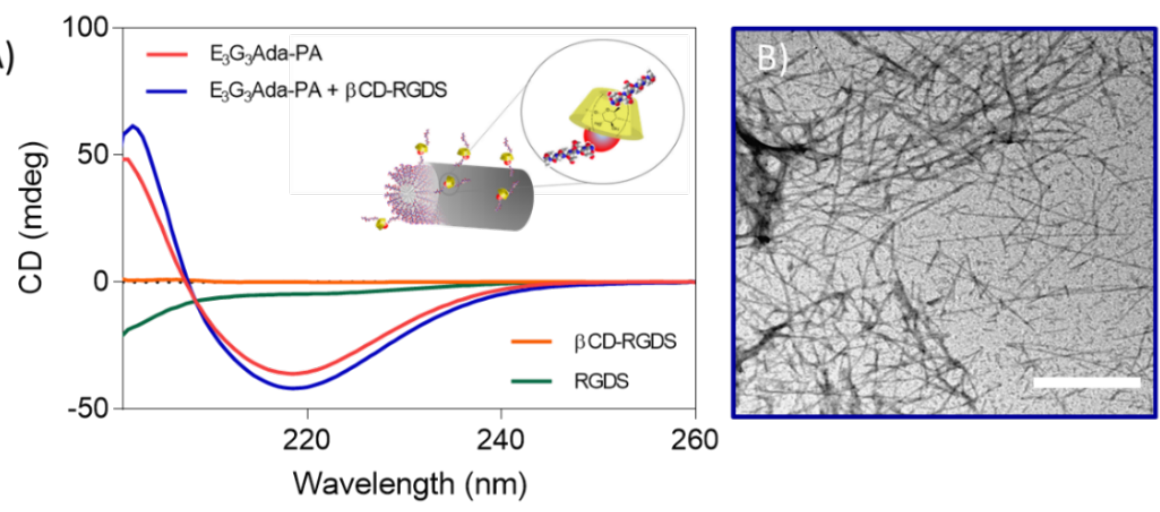

Wavelength $(\mathrm{nm})$
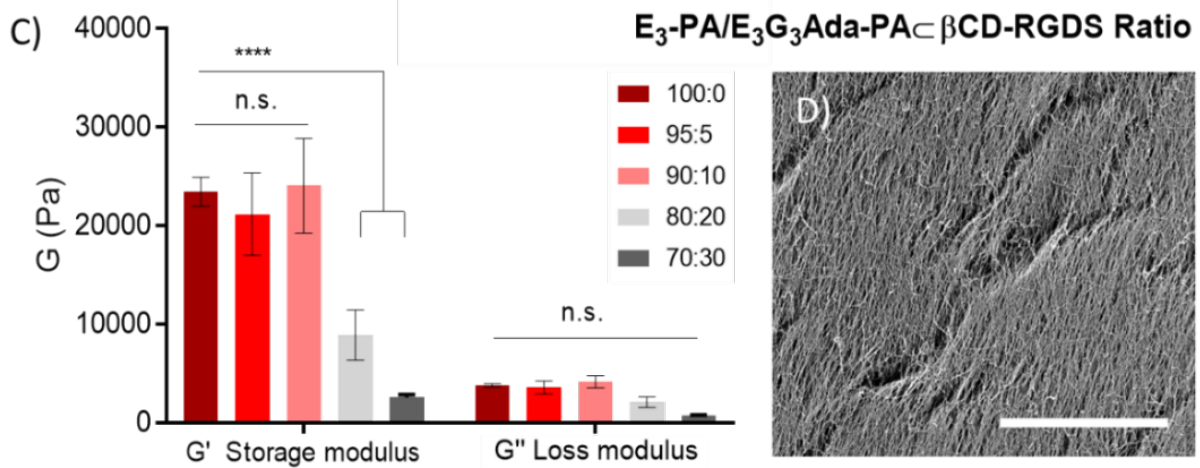

Figure 5. Co-assembly of the $\mathbf{E}_{\mathbf{3}} \mathbf{G}_{3}$ Ada-PA $\subset$ RGDS- $\boldsymbol{\beta} C D$ system. A) CD spectra of free $\mathbf{E}_{3} \mathbf{G}_{3} \mathbf{A d a}$ PA, RGDS- $\boldsymbol{\beta}$ CD, RGDS-Peptide, and a 1:1 molar ratio mixture of $\mathbf{E}_{\mathbf{3}} \mathbf{G}_{\mathbf{3}}$ Ada-PA/RGDS- $\boldsymbol{\beta} C D$ at 25 ${ }^{\circ} \mathrm{C}$. B) TEM micrograph showing the persistence of nanofibers after $\mathbf{E}_{\mathbf{3}} \mathbf{G}_{\mathbf{3}} \mathbf{A d a}-\mathbf{P A} \subset \mathbf{R G D S}-\boldsymbol{\beta C D}$ formation $(1: 1$ molar ratio mixture, scale bar $=500 \mathrm{~nm}) . \mathrm{C})$ Rheological characterisation of coassembled $\mathbf{E}_{\mathbf{3}}-\mathbf{P A} / \mathbf{E}_{\mathbf{3}} \mathbf{G}_{3} \mathbf{A d a}$-PA $\subset$ RGDS- $\boldsymbol{\beta C D}$ hydrogels. Storage $\left(\mathrm{G}^{\prime}\right)$ and loss $\left(\mathrm{G}^{\prime \prime}\right)$ moduli values of different $\mathbf{E}_{\mathbf{3}}-\mathbf{P A} / \mathbf{E}_{\mathbf{3}} \mathbf{G}_{\mathbf{3}}$ Ada-PA $\subset$ RGDS- $\boldsymbol{\beta C D}$ hydrogels $\left(1 \mathrm{wt} \%,\left[\mathrm{CaCl}_{2}\right]=100 \mathrm{mM}\right.$, ****p $<$ 0.0001 ; n.s. no significant difference; $n>3$ ). D) SEM micrograph of a 90:10 thermally treated hydrogel showing the presence of fiber alignment (1:1 host-guest molar ratio, scale bar $=10 \mu \mathrm{m})$.

\section{Ternary E EA $/ \mathbf{E}_{3} \mathrm{G}_{3}$ Ada-PA $\subset$ RGDS- $\beta$ CD hydrogels}

To assess the possibility to co-assemble $\mathbf{E}_{\mathbf{3}}-\mathbf{P A}$ and $\mathbf{E}_{\mathbf{3}} \mathbf{G}_{\mathbf{3}} \mathbf{A d a}-\mathbf{P A} \subset \mathbf{R G D S}-\boldsymbol{\beta} \mathbf{C D}$ into functional hydrogels, mixtures of the three individual peptides were carefully prepared, incubated at $80{ }^{\circ} \mathrm{C}$, and gradually cooled down to room temperature before gelifying them by injection of $\mathrm{CaCl}_{2}$. As expected, ${ }^{32}$ this thermal treatment imprinted the ternary hydrogels with some degree of fiber alignment (Figure 5D). Increasing contents of the Ada-PA $\subset$ RGDS- $\boldsymbol{\beta}$ CD complex led to different stiffness in the resulting hydrogels. Incorporation of 5 and $10 \mathrm{~mol} \%$ Ada-PACRGDS- $\boldsymbol{\beta C D}$ in $\mathbf{E}_{\mathbf{3}}$-PA gels did not significantly affect G' and G'" compared to $100 \mathrm{~mol} \% \mathbf{E}_{\mathbf{3}}-\mathbf{P A}$ hydrogels (Figure 5C, see Figure S6 for a side to side comparison). Moreover, fractions higher than 20 mol\% Ada-PACRGDS- 
BCD decreased G' values from $24 \mathrm{kPa}$ to less than $10 \mathrm{kPa}$, implying a possible detrimental effect in fiber elongation due to electrostatic repulsion or geometric hindrances amid RGDS- $\boldsymbol{\beta}$ CD motifs when present in concentrations higher than $10 \mathrm{~mol} \%$. These results demonstrate that mechanical properties of ternary hydrogels comprising $\mathbf{E}_{\mathbf{3}}-\mathbf{P A}$ and different amounts of non-covalently presented RGDS motifs can be retained as in ummodified $\mathbf{E}_{\mathbf{3}}$-PA gels, or modulated as a function of host-guest complex Ada-PA $\subset$ RGDS- $\boldsymbol{\beta}$ CD concentration.

\section{Non-covalent cell attachment epitope presentation on PA nanofibers}

Knowing that RGDS motifs can be successfully projected out of the PA nanofiber surface via hostguest interactions, we then investigated cell response to this non-covalent epitope anchoring and presenting approach using in vitro fibroblast cultures. NIH-3T3 fibroblasts were cultured atop coasembled $\mathbf{E}_{\mathbf{3}}$-PA hydrogels with increasing fractions of Ada $\subset$ RGDS- $\boldsymbol{\beta C D}$ complex. We hypothesised that increasing contents of host-guest presented RGDS epitopes in the gels would lead to enhanced cell attachment and spreading. Cells were inoculated and incubated for short times $(\leq 3$ h) ${ }^{51}$, fixed, and stained to visualize cell nuclei and actin cytoskeleton (Figure 6A).

Qualitatively, fibroblasts cultured for $30 \mathrm{~min}$ on $\mathbf{E}_{\mathbf{3}}$-PA control hydrogels exhibited little spreading and a rounded morphology, which indicates limited nanofiber recognition. On the other hand, cells cultured atop gels with increasing content of Ada $\subset$ RGDS- $\boldsymbol{\beta}$ CD appeared more spread and with rather angular features (for instance the $30 \mathrm{~min}$ gel with $20 \mathrm{~mol} \%$ of Ada $\subset$ RGDS- $\boldsymbol{\beta C D}$ in Figure 6A). These differences were more noticeable after $3 \mathrm{~h}$ of culture, when cells on $\mathbf{E}_{\mathbf{3}}$-PA control hydrogels were beginning to spread while cells on Ada $\subset$ RGDS- $\boldsymbol{\beta}$ CD gels were well-spread and with a number of cell protruding extensions, indicative of a more advanced stage of adhesion to the hydrogel substrate (Figure 6A). 
In addition, phalloidin staining also revealed noticeable differences in cell cytoskeleton architecture and actin filament arrangement amongst cultures. After $3 \mathrm{~h}$ of culture on $\mathbf{E}_{\mathbf{3}}$-PA control hydrogels, fibroblasts exhibited a homogeneously distributed actin cytoskeleton with short and few stress fibers. ${ }^{52}$ On the contrary, cells cultured on gels with increasing content of the host-guest pair Ada $\subset$ RGDS- $\boldsymbol{\beta C D}$ exhibited increasingly organised networks of longer actin microfilaments, with higher and densely packed contents of actin close to the plasma membrane, a possible indicative of focal adhesion formation as the result of a later spreading stage (Figure 6A). ${ }^{53,54}$

To further confirm these effects, we then quantified this enhanced fibroblast spreading response to host-guest presented RGDS by monitoring changes in fibroblasts morphology. For this purpose, we used the ratio of projected cell area ( $\mathrm{A}_{\mathrm{Cell}}$ indicated by actin content in the cytoskeleton) to cell nucleus area $\left(\mathrm{A}_{\text {Nucleus }}\right.$ indicated by DAPI staining). This ratio $\left(\mathrm{A}_{\mathrm{Cell}} / \mathrm{A}_{\mathrm{Nucleus}}\right)$ allows for projected cell area normalisation resulting in a more thorough comparison between cells with similar projected areas but with different levels of adhesion. Similar ratios are a regular tool in cell morphometry. ${ }^{55}$ The results reveal that cells on hydrogels with increasing fractions of the Ada $\subset$ RGDS- $\boldsymbol{\beta}$ CD complex adhered faster than those on control $\mathbf{E}_{\mathbf{3}}$-PA gels. In these $\mathbf{E}_{\mathbf{3}}$-PA control gels, cell attachment becomes sgnificantly different only after $3 \mathrm{~h}$ of culture (red bars, Figure 6B), while cells on gels with a 10 mol\% fraction of the Ada $\subset$ RGDS- $\beta$ CD complex exhibited significant differences after only $1 \mathrm{~h}$ of culture (dark blue bars, Figure 6B) and gels with a $20 \mathrm{~mol} \%$ content developed differences after just 30 min of culture (sky blue bars, Figure 6B).

As no significant differences were found in cell spreading between samples after 30 min of culture (Figure 6C), we reasoned that only initial cell-substrate contact and passive adhesion are taking place, so events in which the presentation of RGDS from the substrate do not play a relevant role at this early culture stage in all hydrogels. After $1 \mathrm{~h}$ of culture, more spread morphologies were found in 
Ada $\subset$ RGDS- $\boldsymbol{\beta}$ CD containing hydrogels compared to control $\mathbf{E}_{\mathbf{3}}$-PA gels (although no statistical difference was found), indicating that non-covalent presentation of RGDS epitopes on PA nanofibers starts playing a role in receptor-ligand binding after $1 \mathrm{~h}$ culture. ${ }^{28}$ After $3 \mathrm{~h}$ of culture, cells on all Ada $\subset$ RGDS- $\boldsymbol{\beta C D}$ containing hydrogels exhibited significantly different spreading areas compared to $\mathbf{E}_{\mathbf{3}}$-PA controls, indicating that fractions of Ada $\subset$ RGDS- $\boldsymbol{\beta} \mathbf{C D}$ as little as $5 \mathrm{~mol} \%$ are sufficent to trigger late cell spreading events like modulation of cytoskeleton assembly, ${ }^{51}$ focal adhession formation, and cell motility events that have not started to take place in $\mathbf{E}_{\mathbf{3}}$-PA control gels at this 3 h stage (Figure 6C).

All hydrogel systems were treated with the same supplemented cell culture media, and the fact that the observed increase in cell spreading in RGDS containing hydrogels -but not in $\mathbf{E}_{\mathbf{3}}$-PA control onessuggests that cell adhesion is mostly being affected by Ada $\subset$ RGDS- $\boldsymbol{\beta}$ CD content $^{56}$ rather than due serum proteins from the cell culture media adsorbed onto nanofibers' surface during these early culture stages. Aditional control hydrogels comprising an excess of filler $\mathbf{E}_{\mathbf{3}}-\mathbf{P A}$ and $10 \mathrm{~mol} \%$ of either $\mathbf{E}_{\mathbf{3}} \mathbf{G}_{\mathbf{3}}$-PA/RGDS- $\boldsymbol{\beta}$ CD (lacking Ada binding units, see Table S1) or $\mathbf{E}_{\mathbf{3}} \mathbf{G}_{\mathbf{3}} \mathbf{A d a}-\mathbf{P A} / \mathbf{R G D S}$ (lacking $\beta \mathrm{CD}$ binding units) exhibited no difference in cell morphology and spreading compared to $\mathbf{E}_{\mathbf{3}}$-PA gels (even after $3 \mathrm{~h}$ culture). This indicates that the desired host-guest-mediated epitope presentation is mostly responsible for the observed cell attachment (Figure 6) rather than unspecific/non-optimal electrostatic adsorption of RGDS- $\boldsymbol{\beta C D}$ units to the nanofibers. ${ }^{29}$

The above presented cell studies focus on cell events relevant only a few hours after seeding atop the hydrogels. However, longer term studies on NIH-3T3 cell viability assays performed in host-guest PA hydrogels very similar to our gels have shown cell growth for up to 7 days. ${ }^{18}$ Overall, the above discussed results indicate that host-guest interactions are fitting to perform presentation of RGDS epitopes on PA nanofibers. 
Incorporation of RGD-based sequences in PA hydrogels for cell adhesion and cell delivery studies has been traditionally made via covalent approaches, including variations on: linear, ${ }^{27,57}$ branched, or cyclic $^{28}$ peptide conformations, the presence of a spacer in the PA sequence, ${ }^{29,58}$ epitope density along nanofiber axis ${ }^{30}$, and hierarchical structuration of peptide constructs. ${ }^{31}$ RGD presentation in all of these systems relies on the covalent binding of the epitope to monomeric units prior to self-assembly, other supramolecular polymer-based systems, such as those based on Fmoc, ${ }^{59,60}$ 2-ureido-4[1H]pyrimidinone $(\mathrm{UPy})^{61}$ or bisurea ${ }^{62}$ motifs, follow a similar strategy. Though recently published systems immobilise RGD epitopes on poly-methacrylate-based cryogels via host-guest-based interactions, ${ }^{63}$ our platform's polymer network formation, and both epitope anchoring and presentation, rely entirely on molecular self-assembly and non-covalent interactions.

A)

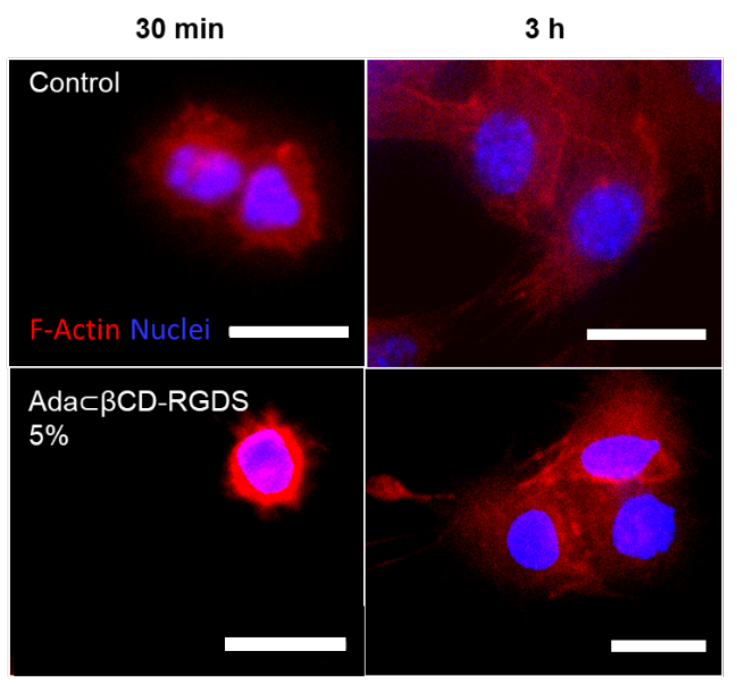

B)

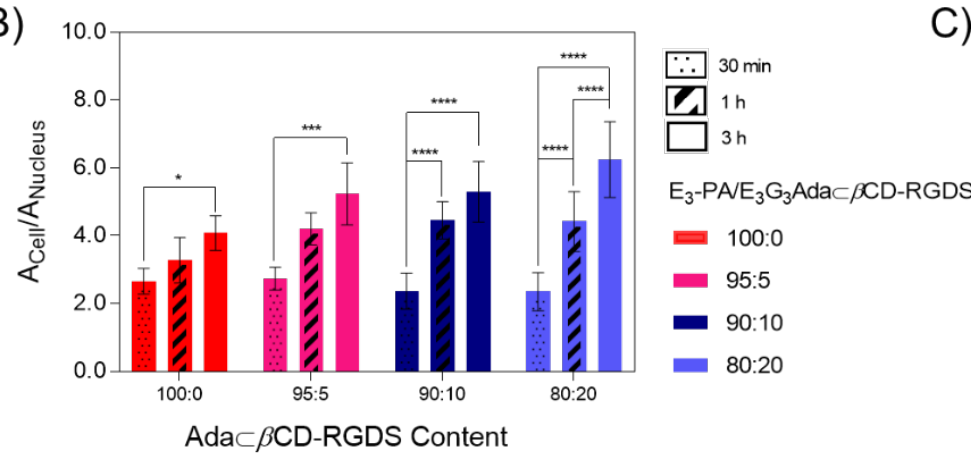

$30 \mathrm{~min}$

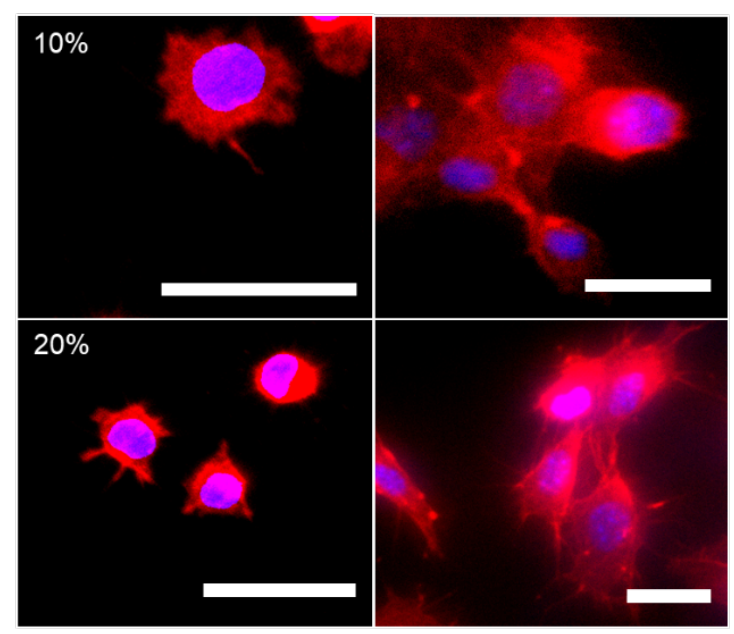

C)

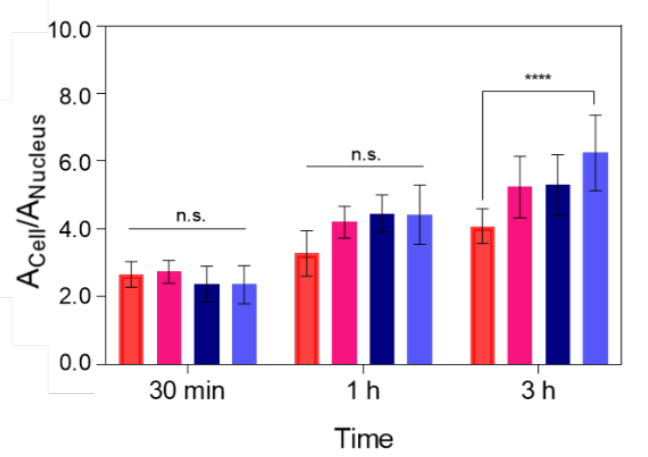

Figure 6. Effect of host-guest-mediated presentation of RGDS motifs on NIH-3T3 fibroblasts attachment to $\mathbf{E}_{3}-\mathbf{P A} / \mathbf{E}_{3} \mathbf{G}_{3}$ Ada-PA $\subset \boldsymbol{\beta C D}$-RGDS hydrogels. A) Confocal microscopy images of NIH-3T3 fibroblasts attached to hydrogels with an increasing content of $\mathbf{E}_{\mathbf{3}} \mathbf{G}_{\mathbf{3}}$ Ada-PA $\subset \boldsymbol{\beta C D}$-RGDS 
units (red staining: Fallodin-rhodamine for F-actin, blue: DAPI for cell nuclei, scale bar $=50 \mu \mathrm{m}$ ). B) NIH-3T3 fibroblast attachment quantified as a function of Ada-PA $\subset \boldsymbol{\beta C D - R G D S ~ c o n t e n t , ~ a n d ~ C ) ~ a s ~}$ a function of time (n.s.: no significant difference, $* \mathrm{p}<0.1, * * * \mathrm{p}<0.001, * * * * \mathrm{p}<0.0001$ ).

Reports on high-density epitope presentation in PA-based hydrogels typically involve the use of a 1$20 \mathrm{~mol} \%$ range of epitope bearing-PA monomers. ${ }^{57,58,64}$ Our non-covalent epitope presentation approach works on this content range and shows similar cell adhesion efficacies compared to these PA systems (for example, the study by fibronecting and co-workers might be the most suitable for comparison in this regard). ${ }^{29}$ Our system also exhibited comparable cell adhesion performance to other supramolecular polymer systems, including 4 mol\% RGD-bearing UPy ${ }^{62}$ or bisureas fibrous ${ }^{65}$ scaffolds. It is worth mentioning that even though the high affinity of Ada moieties for the $\beta \mathrm{CD}$ cavity $(\log \mathrm{K}=5.04)^{43}$ ensures that the vast majority of these units remain bound, there will be always a minute amount of free host species in solution, therefore eliciting possible unanticipated cell responses. Studies on these types of material highlight the complexity of cell-dynamic biomaterials interactions, emphasizing that their responsive capacity to environment stimuli can be considered advantageous. However, extra care must be taken when interpreting biological results if the goal of using these materials is to mimic the ECM. ${ }^{62}$

Our non-covalent epitope anchoring and presentation approach not only enables similar cell responses as other self-assembled systems, but allows for ease of preparation (simply by mixing filler and hostguest peptide monomers in the desired ratiometric amounts), it grants the possibility to precisely space Ada-PA moities along nanofibers by varying the content of filler-PA (offering control over subsequent positioning of host-epitope units), ${ }^{30}$ and presents several advantages over conventional covalent epitope bearing strategies. For instance, nanofiber decoration can be achieved as the fiber assembles (pre-assembly functionalization) or can be performed once nanofibers have assembled (post-assembly functionalization), thus facilitating versatility and tuneability of the resulting gels. ${ }^{47}$ 
Our approach allows the possibility to incorporate multiple epitopes at a time along nanofibers, favoring the concomitant and synergistic presentation of several biological cues, as for instance the RGDS and PHSRN sequences from fibronectin (known to bind $\alpha_{5} \beta_{1}$ integrin and to promote spreading of endothelial cells). ${ }^{66}$ Its modular and stage-assembly nature might also allow to present biosignals whose covalent inclusion into a PA monomer sequence might prove synthetically demanding, as a result of the peptide sequence length, low overall synthesis yield or solubility issues hampering further purification. In addition, the reversible nature of the non-covalent epitope binding might broaden the conformational propensities of larger epitopes (larger than RGDS) by presenting them under new rotational dynamics. For instance, those imposed by fast rotation of Ada units around the $\beta$ CD symmetry axis ${ }^{67}$ (something unachievable as part of a longer peptide backbone), which might elicit new spectra of cell responses to the material as a function of a particular host-guest system of choice. $^{1}$

Lastly, by choosing a suitable host-guest pair that is stimuli-responsive ${ }^{43}$ (e.g. via light-responsive systems like azobenzenes $)^{68}$ biorrelevant epitopes of choice could be selectively attached or detached to PA nanofibers, allowing their reversible presentation. This approach aims to broaden our current capacity to provide synthetic matrixes with temporal control over complex physiological processes as a function of the desired biomedical application.

\section{CONCLUSIONS}

In this study, we have introduced and demonstrated the efficacy of a new high-density epitope presentation strategy on self-assembled PA scaffolds mediated by non-covalent interactions. This approach is based on the host-guest-mediated presentation of RGDS epitopes and led to increased PA nanofiber bioactivity. Increasing concentrations of non-covalently attached RGDS epitopes correlated with incremented cell adhesion, spreading, and actin organisation. This approach expands 
the toolbox for the molecular design of functional synthetic ECMs for tissue engineering and regenerative medicine applications.

\section{SUPPORTING INFORMATION}

Electronic supporting information is available online describing peptide synthesis, purification, rheological data corresponding to the hydrogels as well as in vitro cell culture results.

\section{ACKNOWLEDGEMENTS}

This work was financially supported by the European Research Council (ERC) Starting Grant (STROFUNSCAFF), the UK Regenerative Medicine Platform (UKRMP2) Acellular/Smart Materials, and the Program for Innovation and Human Capital from the Ministry of Science, Technology and Telecommunications of the Government of Costa Rica (MICITT-PINN-PED-0142015-2). The authors thank everyone in the Mata and Azevedo Groups for valuable discussions. 


\section{REFERENCES}

(1) Webber, M. J.; Appel, E. A.; Meijer, E. W.; Langer, R. Supramolecular Biomaterials. Nat. Mater. 2015, 15 (1), 13-26. https://doi.org/10.1038/nmat4474.

(2) Mendes, A. C.; Baran, E. T.; Reis, R. L.; Azevedo, H. S. Self-Assembly in Nature: Using the Principles of Nature to Create Complex Nanobiomaterials. Wiley Interdiscip. Rev. Nanomedicine Nanobiotechnology 2013, 5 (6), 582-612. https://doi.org/10.1002/wnan.1238.

(3) Paolino, M.; Ennen, F.; Lamponi, S.; Cernescu, M.; Voit, B.; Cappelli, A.; Appelhans, D.; Komber, H. Cyclodextrin-Adamantane Host-Guest Interactions on the Surface of Biocompatible Adamantyl-Modified Glycodendrimers. Macromolecules 2013, 46 (9), 32153227. https://doi.org/10.1021/ma400352m.

(4) Delbianco, M.; Bharate, P.; Varela-Aramburu, S.; Seeberger, P. H. Carbohydrates in Supramolecular Chemistry. Chem. Rev. 2016, $116 \quad$ (4), 1693-1752. https://doi.org/10.1021/acs.chemrev.5b00516.

(5) Buchberger, A.; Simmons, C. R.; Fahmi, N. E.; Freeman, R.; Stephanopoulos, N. Hierarchical Assembly of Nucleic Acid/Coiled-Coil Peptide Nanostructures. J. Am. Chem. Soc. 2020, jacs.9b11158. https://doi.org/10.1021/jacs.9b11158.

(6) Garcia-Seisdedos, H.; Empereur-Mot, C.; Elad, N.; Levy, E. D. Proteins Evolve on the Edge of Supramolecular Self-Assembly. Nature 2017, $548 \quad$ (7666), 244-247. https://doi.org/10.1038/nature23320.

(7) Okesola, B. O.; Mata, A. Multicomponent Self-Assembly as a Tool to Harness New Properties from Peptides and Proteins in Material Design. Chem. Soc. Rev. 2018, 47 (10), 3721-3736. https://doi.org/10.1039/c8cs00121a.

(8) Silva, R.; Fabry, B.; Boccaccini, A. R. Fibrous Protein-Based Hydrogels for Cell Encapsulation. $\quad$ Biomaterials $\quad$ 2014, $\quad 35 \quad$ (25), $\quad$ 6727-6738. 
https://doi.org/10.1016/j.biomaterials.2014.04.078.

(9) Prince, E.; Kumacheva, E. Design and Applications of Man-Made Biomimetic Fibrillar Hydrogels. Nat. Rev. Mater. 2019, 4 (2), 99-115. https://doi.org/10.1038/s41578-018-0077-9.

(10) Caliari, S. R.; Burdick, J. A. A Practical Guide to Hydrogels for Cell Culture. Nat. Methods 2016, 13 (5), 405-414. https://doi.org/10.1038/nmeth.3839.

(11) Okesola, B. O.; Redondo-Gómez, C.; Mata, A. Multicomponent Self-Assembly: Supramolecular Design of Complex Hydrogels for Biomedical Applications. In Selfassembling Biomaterials; Elsevier, 2018; pp 371-397. https://doi.org/10.1016/B978-0-08102015-9.00019-8.

(12) Dou, Q.; Wei, Z.; Low, K.; Zhang, K.; Loh, X. J. RSC Advances. RSC Adv. 2017, 7, 2744927453. https://doi.org/10.1039/C7RA03214E.

(13) Kumar, D.; Workman, V. L.; O’Brien, M.; McLaren, J.; White, L.; Ragunath, K.; Rose, F.; Saiani, A.; Gough, J. E. Peptide Hydrogels—A Tissue Engineering Strategy for the Prevention of Oesophageal Strictures. Adv. Funct. Mater. 2017, $27 \quad$ (38). https://doi.org/10.1002/adfm.201702424.

(14) Ghosh, M.; Halperin-Sternfeld, M.; Grigoriants, I.; Lee, J.; Nam, K. T.; Adler-Abramovich, L. Arginine-Presenting Peptide Hydrogels Decorated with Hydroxyapatite as Biomimetic Scaffolds for Bone Regeneration. Biomacromolecules 2017, 18 (11), 3541-3550. https://doi.org/10.1021/acs.biomac.7b00876.

(15) Webber, M. J.; Tongers, J.; Newcomb, C. J.; Marquardt, K.-T.; Bauersachs, J.; Losordo, D. W.; Stupp, S. I. Supramolecular Nanostructures That Mimic VEGF as a Strategy for Ischemic Tissue Repair. Proc. Natl. Acad. Sci. 2011, 108 (33), 13438-13443. https://doi.org/10.1073/pnas. 1016546108.

(16) Mammadov, R.; Mammadov, B.; Toksoz, S.; Aydin, B.; Yagci, R.; Tekinay, A. B.; Guler, M. 
O. Heparin Mimetic Peptide Nanofibers Promote Angiogenesis. Biomacromolecules 2011, 12 (10), 3508-3519. https://doi.org/10.1021/bm200957s.

(17) Hartgerink, J. D.; Beniash, E.; Stupp, S. I. Self-Assembly and Mineralization of PeptideAmphiphile Nanofibers. Science (80-. ). 2001, 294 (5547), 1684-1688. https://doi.org/10.1126/science.1063187.

(18) Redondo-Gómez, C.; Abdouni, Y.; Becer, C. R.; Mata, A. Self-Assembling Hydrogels Based on a Complementary Host-Guest Peptide Amphiphile Pair. Biomacromolecules 2019, 20 (6), 2276-2285. https://doi.org/10.1021/acs.biomac.9b00224.

(19) Pashuck, E. T.; Cui, H.; Stupp, S. I. Tuning Supramolecular Rigidity of Peptide Fibers through Molecular Structure. J. Am. Chem. Soc. 2010, 132 (17), 6041-6046. https://doi.org/10.1021/ja908560n.

(20) Dagdas, Y. S.; Tombuloglu, A.; Tekinay, A. B.; Dana, A.; Guler, M. O. Interfiber Interactions Alter the Stiffness of Gels Formed by Supramolecular Self-Assembled Nanofibers. Soft Matter 2011, 7 (7), 3524-3532. https://doi.org/10.1039/c0sm01089h.

(21) Okesola, B. O.; Lau, H. K.; Derkus, B.; Boccorh, D. K.; Wu, Y.; Wark, A. W.; Kiick, K. L.; Mata, A. Covalent Co-Assembly between Resilin-like Polypeptide and Peptide Amphiphile into Hydrogels with Controlled Nanostructure and Improved Mechanical Properties. Biomater. Sci. 2020, 846-857. https://doi.org/10.1039/c9bm01796h.

(22) Hedegaard, C. L.; Collin, E. C.; Redondo-Gómez, C.; Nguyen, L. T. H.; Ng, K. W.; CastrejónPita, A. A.; Castrejón-Pita, J. R.; Mata, A. Hydrodynamically Guided Hierarchical SelfAssembly of Peptide-Protein Bioinks. Adv. Funct. Mater. 2018, 28 (16), 1-13. https://doi.org/10.1002/adfm.201703716.

(23) Inostroza-brito, K. E.; Collin, E.; Siton-mendelson, O.; Smith, K. H.; Monge-marcet, A.; Ferreira, D. S.; Rodríguez, R. P.; Alonso, M.; Rodríguez-cabello, J. C.; Reis, R. L.; et al. Co- 
Assembly, Spatiotemporal Control and Morphogenesis of a Hybrid Protein-Peptide System. Nat. Chem. 2015, No. September, 1-8. https://doi.org/10.1038/nchem.2349.

(24) Capito, R. M.; Azevedo, H. S.; Velichko, Y. S.; Mata, A.; Stupp, S. I. Self-Assembly of Large and Small Molecules into Hierarchically Ordered Sacs and Membranes. Science (80-. ). 2008, 319 (5871), 1812-1816. https://doi.org/10.1126/science.1154586.

(25) Okesola, B. O.; Wu, Y.; Derkus, B.; Gani, S.; Wu, D.; Knani, D.; Smith, D. K.; Adams, D. J.; Mata, A. Supramolecular Self-Assembly to Control Structural and Biological Properties of Multicomponent Hydrogels. Chem. Mater. 2019, 31 (19), 7883-7897. https://doi.org/10.1021/acs.chemmater.9b01882.

(26) Okesola, B. O.; Ni, S.; Derkus, B.; Galeano, C. C.; Hasan, A.; Wu, Y.; Ramis, J.; Buttery, L.; Dawson, J. I.; Este, M. D.; et al. Growth-Factor Free Multicomponent Nanocomposite Hydrogels That Stimulate Bone Formation. 2020, 1906205, 1-13. https://doi.org/10.1002/adfm.201906205.

(27) Huang, Z.; Newcomb, C. J.; Bringas, P.; Stupp, S. I.; Snead, M. L. Biological Synthesis of Tooth Enamel Instructed by an Artificial Matrix. Biomaterials 2010, 31 (35), 9202-9211. https://doi.org/10.1016/j.biomaterials.2010.08.013.

(28) Storrie, H.; Guler, M. O.; Abu-Amara, S. N.; Volberg, T.; Rao, M.; Geiger, B.; Stupp, S. I. Supramolecular Crafting of Cell Adhesion. Biomaterials 2007, 28 (31), 4608-4618. https://doi.org/10.1016/j.biomaterials.2007.06.026.

(29) Sur, S.; Tantakitti, F.; Matson, J. B.; Stupp, S. I. Epitope Topography Controls Bioactivity in Supramolecular Nanofibers. Biomater. Sci. 2015, 3 (3), 520-532. https://doi.org/10.1039/c4bm00326h.

(30) Webber, M. J.; Tongers, J.; Renault, M. A.; Roncalli, J. G.; Losordo, D. W.; Stupp, S. I. Development of Bioactive Peptide Amphiphiles for Therapeutic Cell Delivery. Acta Biomater. 
2010, 6 (1), 3-11. https://doi.org/10.1016/j.actbio.2009.07.031.

(31) Berns, E. J.; Sur, S.; Pan, L.; Goldberger, J. E.; Suresh, S.; Zhang, S.; Kessler, J. A.; Stupp, S. I. Aligned Neurite Outgrowth and Directed Cell Migration in Self-Assembled Monodomain Gels. Biomaterials 2014, 35 (1), 185-195. https://doi.org/10.1016/j.biomaterials.2013.09.077.

(32) Zhang, S.; Greenfield, M. A.; Mata, A.; Palmer, L. C.; Bitton, R.; Mantei, J. R.; Aparicio, C.; de la Cruz, M. O.; Stupp, S. I. A Self-Assembly Pathway to Aligned Monodomain Gels. Nat. Mater. 2010, 9 (7), 594-601. https://doi.org/10.1038/nmat2778.

(33) Mata, A.; Hsu, L.; Capito, R.; Aparicio, C.; Henrikson, K.; Stupp, S. I. Micropatterning of

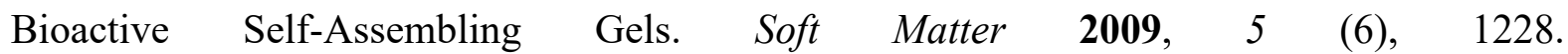
https://doi.org/10.1039/b819002j.

(34) Silva, G. A.; Czeisler, C.; Niece, K. L.; Beniash, E.; Harrington, D. A.; Kessler, J. A.; Stupp, S. I. Selective Differentiation of Neural Progenitor Cells by High-Epitope Density Nanofibers. Science (80-. ). 2004, 303 (5662), 1352-1355. https://doi.org/10.1126/science.1093783.

(35) Shah, R. N.; Shah, N. A.; Del Rosario Lim, M. M.; Hsieh, C.; Nuber, G.; Stupp, S. I. Supramolecular Design of Self-Assembling Nanofibers for Cartilage Regeneration. Proc. Natl. Acad. Sci. 2010, 107 (8), 3293-3298. https://doi.org/10.1073/pnas.0906501107.

(36) McClendon, M. T.; Yalom, A.; Berns, E. J.; Hokugo, A.; Stupp, S. I.; Jarrahy, R.; Spigelman, I.; Li, A.; Stephanopoulos, N.; Segovia, L. A. A Bioengineered Peripheral Nerve Construct Using Aligned Peptide Amphiphile Nanofibers. Biomaterials 2014, 35 (31), 8780-8790. https://doi.org/10.1016/j.biomaterials.2014.06.049.

(37) Mata, A.; Geng, Y.; Henrikson, K. J.; Aparicio, C.; Stock, S. R.; Satcher, R. L.; Stupp, S. I. Bone Regeneration Mediated by Biomimetic Mineralization of a Nanofiber Matrix. Biomaterials 2010, 31 (23), 6004-6012. https://doi.org/10.1016/j.biomaterials.2010.04.013.

(38) Sur, S.; Matson, J. B.; Webber, M. J.; Newcomb, C. J.; Stupp, S. I. Photodynamic Control of 
Bioactivity in a Nanofiber Matrix. ACS Nano 2012, 6 (12), 10776-10785. https://doi.org/10.1021/nn304101x.

(39) Rosales, A. M.; Anseth, K. S. The Design of Reversible Hydrogels to Capture Extracellular Matrix Dynamics. Nat. Rev. Mater. 2016, 1 (2), 1-15. https://doi.org/10.1038/natrevmats.2015.12.

(40) Kloxin, A. M.; Kasko, A. M.; Salinas, C. N.; Anseth, K. S. Photodegradable Hydrogels for Dynamic Tuning of Physical and Chemical Properties. Science (80-. ). 2009, 324 (5923), 5963. https://doi.org/10.1126/science.1169494.

(41) Roberts, J. N.; Sahoo, J. K.; McNamara, L. E.; Burgess, K. V.; Yang, J.; Alakpa, E. V.; Anderson, H. J.; Hay, J.; Turner, L. A.; Yarwood, S. J.; et al. Dynamic Surfaces for the Study of Mesenchymal Stem Cell Growth through Adhesion Regulation. ACS Nano 2016, 10 (7), 6667-6679. https://doi.org/10.1021/acsnano.6b01765.

(42) Mann, J. L.; Yu, A. C.; Agmon, G.; Appel, E. A. Supramolecular Polymeric Biomaterials. Biomater. Sci. 2018, 6 (1), 10-37. https://doi.org/10.1039/c7bm00780a.

(43) Schmidt, B. V. K. J.; Barner-Kowollik, C. Dynamic Macromolecular Material Design-The Versatility of Cyclodextrin-Based Host-Guest Chemistry. Angew. Chemie - Int. Ed. 2017, 56 (29), 8350-8369. https://doi.org/10.1002/anie.201612150.

(44) Rosales, A. M.; Rodell, C. B.; Chen, M. H.; Morrow, M. G.; Anseth, K. S.; Burdick, J. A. Reversible Control of Network Properties in Azobenzene-Containing Hyaluronic Acid-Based Hydrogels. Bioconjug. Chem. 2018, $29 \quad$ (4), 905-913. https://doi.org/10.1021/acs.bioconjchem.7b00802.

(45) Wong, L. Y.; Xia, B.; Wolvetang, E.; Cooper-White, J. Targeted, Stimuli-Responsive Delivery of Plasmid DNA and MiRNAs Using a Facile Self-Assembled Supramolecular Nanoparticle $\begin{array}{lllll}\text { System. } & \text { Biomacromolecules } & \mathbf{2 0 1 8}, & 19 & \text { (2), }\end{array}$ 
https://doi.org/10.1021/acs.biomac.7b01462.

(46) Shi, Y.; Goodisman, J.; Dabrowiak, J. C. Cyclodextrin Capped Gold Nanoparticles as a Delivery Vehicle for a Prodrug of Cisplatin. Inorg. Chem. 2013, 52 (16), 9418-9426. https://doi.org/10.1021/ic400989v.

(47) Khan, S.; Sur, S.; Dankers, P. Y. W.; da Silva, R. M. P.; Boekhoven, J.; Poor, T. A.; Stupp, S. I. Post-Assembly Functionalization of Supramolecular Nanostructures with Bioactive Peptides and Fluorescent Proteins by Native Chemical Ligation. Bioconjug. Chem. 2014, 25 (4), $707-$ 717. https://doi.org/10.1021/bc400507v.

(48) Tantakitti, F.; Boekhoven, J.; Wang, X.; Kazantsev, R. V.; Yu, T.; Li, J.; Zhuang, E.; Zandi, R.; Ortony, J. H.; Newcomb, C. J.; et al. Energy Landscapes and Functions of Supramolecular Systems. Nat. Mater. 2016, 15 (4), 469-476. https://doi.org/10.1038/nmat4538.

(49) Huettner, N.; Dargaville, T. R.; Forget, A. Discovering Cell-Adhesion Peptides in Tissue Engineering: Beyond RGD. Trends Biotechnol. 2018, 36 (4), 372-383. https://doi.org/10.1016/j.tibtech.2018.01.008.

(50) Xiong, J. P.; Stehle, T.; Zhang, R.; Joachimiak, A.; Frech, M.; Goodman, S. L.; Arnaout, M. A. Crystal Structure of the Extracellular Segment of Integrin AV $\beta 3$ in Complex with an ArgGly-Asp Ligand. Science (80-. $\quad$ ). $\quad \mathbf{2 0 0 2 ,} 296 \quad$ (5565), 151-155. https://doi.org/10.1126/science.1069040.

(51) Humphries, M. J. Cell Adhesion Assays. In Methods in Molecular Biology, Extracellular Matrix Protocols, vol. 522; 2009; pp 203-210. https://doi.org/10.1007/978-1-59745-413-1_14.

(52) Pellegrin, S.; Mellor, H. Actin Stress Fibers. J. Cell Sci. 2007, 120 (20), 3491-3499. https://doi.org/10.1242/jcs.018473.

(53) McGrath, J. L. Cell Spreading: The Power to Simplify. Curr. Biol. 2007, 17 (10), 357-358. https://doi.org/10.1016/j.cub.2007.03.057. 
(54) Parsons, J. T.; Horwitz, A. R.; Schwartz, M. A. Cell Adhesion: Integrating Cytoskeletal Dynamics and Cellular Tension. Nat. Rev. Mol. Cell Biol. 2010, 11 (9), 633-643. https://doi.org/10.1038/nrm2957.

(55) Su Lim, C.; Sun Kim, E.; Yeon Kim, J.; Taek Hong, S.; Jai Chun, H.; Eun Kang, D.; Rae Cho, B. Measurement of the Nucleus Area and Nucleus/Cytoplasm and Mitochondria/Nucleus Ratios in Human Colon Tissues by Dual-Colour Two-Photon Microscopy Imaging. Sci. Rep. 2015, 5 (1), 18521. https://doi.org/10.1038/srep18521.

(56) Sur, S.; Newcomb, C. J.; Webber, M. J.; Stupp, S. I. Tuning Supramolecular Mechanics to Guide Neuron Development. Biomaterials 2013, $34 \quad$ (20), 4749-4757. https://doi.org/10.1016/j.biomaterials.2013.03.025.

(57) Ferreira, D. S.; Marques, A. P.; Reis, R. L.; Azevedo, H. S. Hyaluronan and Self-Assembling Peptides as Building Blocks to Reconstruct the Extracellular Environment in Skin Tissue. Biomater. Sci. 2013, 1 (9), 952. https://doi.org/10.1039/c3bm60019j.

(58) Radvar, E.; Azevedo, H. S. Supramolecular Nanofibrous Peptide/Polymer Hydrogels for the Multiplexing of Bioactive Signals. ACS Biomater. Sci. Eng. 2019, 5 (9), 4646-4656. https://doi.org/10.1021/acsbiomaterials.9b00941.

(59) Zhou, M.; Smith, A. M.; Das, A. K.; Hodson, N. W.; Collins, R. F.; Ulijn, R. V.; Gough, J. E. Self-Assembled Peptide-Based Hydrogels as Scaffolds for Anchorage-Dependent Cells. Biomaterials 2009, 30 (13), 2523-2530. https://doi.org/10.1016/j.biomaterials.2009.01.010.

(60) Rodriguez, A. L.; Wang, T. Y.; Bruggeman, K. F.; Horgan, C. C.; Li, R.; Williams, R. J.; Parish, C. L.; Nisbet, D. R. In Vivo Assessment of Grafted Cortical Neural Progenitor Cells and Host Response to Functionalized Self-Assembling Peptide Hydrogels and the Implications for Tissue Repair. J. Mater. Chem. B 2014, 2 (44), 7771-7778. https://doi.org/10.1039/c4tb01391c. 
(61) Dankers, P. Y. W.; Boomker, J. M.; Huizinga-van der Vlag, A.; Wisse, E.; Appel, W. P. J.; Smedts, F. M. M.; Harmsen, M. C.; Bosman, A. W.; Meijer, W.; van Luyn, M. J. A. Bioengineering of Living Renal Membranes Consisting of Hierarchical, Bioactive Supramolecular Meshes and Human Tubular Cells. Biomaterials 2011, 32 (3), 723-733. https://doi.org/10.1016/j.biomaterials.2010.09.020.

(62) Mollet, B. B.; Comellas-Aragonès, M.; Spiering, A. J. H.; Söntjens, S. H. M.; Meijer, E. W.; Dankers, P. Y. W. A Modular Approach to Easily Processable Supramolecular Bilayered Scaffolds with Tailorable Properties. J. Mater. Chem. B 2014, 2 (17), 2483-2493. https://doi.org/10.1039/c3tb21516d.

(63) Luong, T. D.; Zoughaib, M.; Garifullin, R.; Kuznetsova, S.; Guler, M. O.; Abdullin, T. I. In Situ Functionalization of Poly(Hydroxyethyl Methacrylate) Cryogels with Oligopeptides via $\beta$-Cyclodextrin-Adamantane Complexation for Studying Cell-Instructive Peptide Environment. ACS Appl. Bio Mater. 2019, acsabm.9b01059. https://doi.org/10.1021/acsabm.9b01059.

(64) Webber, M. J.; Tongers, J.; Renault, M. A.; Roncalli, J. G.; Losordo, D. W.; Stupp, S. I. Development of Bioactive Peptide Amphiphiles for Therapeutic Cell Delivery. Acta Biomater. 2010, 6 (1), 3-11. https://doi.org/10.1016/j.actbio.2009.07.031.

(65) van Gaal, R. C.; Buskermolen, A. B. C.; Ippel, B. D.; Fransen, P.-P. K. H.; Zaccaria, S.; Bouten, C. V. C.; Dankers, P. Y. W. Functional Peptide Presentation on Different Hydrogen Bonding Biomaterials Using Supramolecular Additives. Biomaterials 2019, 224 (September), 119466. https://doi.org/10.1016/j.biomaterials.2019.119466.

(66) Pashuck, E. T.; Duchet, B. J. R.; Hansel, C. S.; Maynard, S. A.; Chow, L. W.; Stevens, M. M. Controlled Sub-Nanometer Epitope Spacing in a Three-Dimensional Self-Assembled Peptide Hydrogel. ACS Nano 2016, 10 (12), 11096-11104. https://doi.org/10.1021/acsnano.6b05975. 
(67) TOŠNER, Z; ASKI, S. N.; KOWALEWSKI, J. Rotational Dynamics of Adamantanecarboxylic Acid in Complex with $\beta$-Cyclodextrin. J. Incl. Phenom. Macrocycl. Chem. 2006, 55 (1-2), 59-70. https://doi.org/10.1007/s10847-005-9019-4.

(68) Kadem, L. F.; Suana, K. G.; Holz, M.; Wang, W.; Westerhaus, H.; Herges, R.; Selhuber-Unkel, C. High-Frequency Mechanostimulation of Cell Adhesion. Angew. Chemie - Int. Ed. 2017, 56 (1), 225-229. https://doi.org/10.1002/anie.201609483. 
FOR TABLE OF CONTENTS ONLY

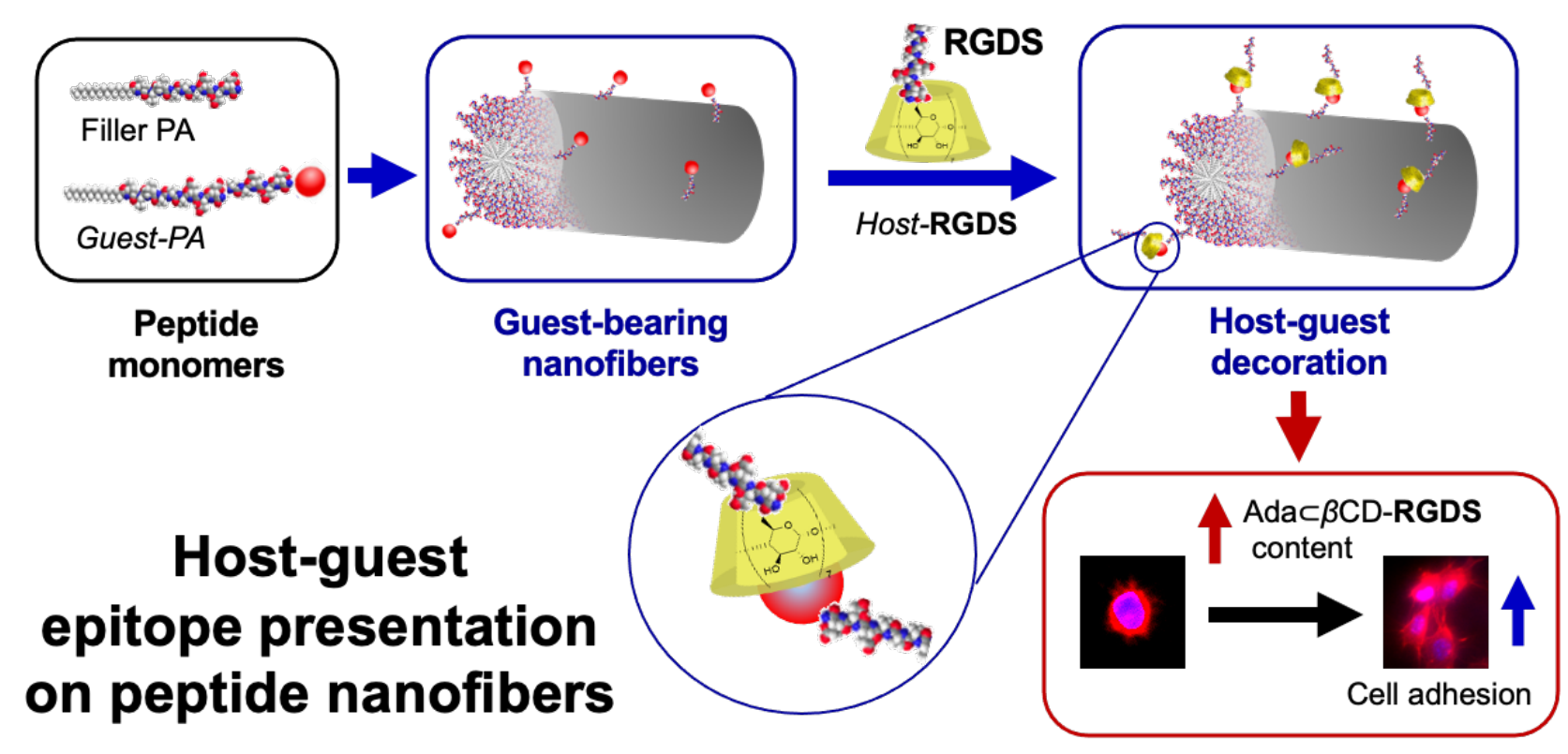

Functional hydrogels 